\title{
ALGUNAS CONSTRUCCIONES DE TIPO COLONIAL EN QUINTANA ROO ${ }^{1}$
}

POR

\begin{abstract}
ALBERTO ESCALONA RAMOS
\end{abstract}
ASI todas las construcciones coloniales que aquí se mencionan se encuentran muy deterioradas a causa de que quedaron abandonadas después de la llamada Guerra de Castas, que tuvo lugar a mediados del siglo pasado entre los indios mayas y la población blanca de la península de Yucatán. A varias de ellas las cubre todavía una espesa vegetación.

Estos informes son nada más un anticipo a una exploración más completa de todas las construcciones que existen de este tipo en el Territorio. Se les distribuye más bien por asuntos y estilos que por regiones: siete templos, un edificio municipal, una fuente, un pozo, un fortín. Como los templos pueden agruparse en tres tipos o estilos, no se dan más informes sobre otras, ya que todas entran dentro de ellos. (Uno de los mapas que acompaña al informe, referente a los indigenas del centro del Territo-

1 Este eatudio es parte del informe de la Expedición Cientifica Mexicana, realizada en la zona maya de Quintana Roo y en territorios de Belice y Guatemala, el año de 1937. 
rio, indica el sitio en que se encuentra carla construcción.) Los tipos de templos son los siguientes:

I. Capillas abiertas.

II. Templos sin contrafuertes y techos de tejado.

III. Templos con contrafuertes y techos abovedados.

Se incluyen entre ellos el templo mayor y la capilla abierta de Santa Cruz, no obstante haber sido construidos hasta 1860 , a raiz de la Guerra de Castas, por estar hechos según las plantas de los templos coloniales de Yucatán.

CAPILLA ABIERTA DEL SIGLO XVI

Al sur del Territorio de Quintana Roo existen las ruinas de una capilla abierta de mediados del siglo xvi, perteneciente a lo que fué Villa Real, fundada por Alonso de Avila en 1532. Está situada a 800 ó 1,000 metros al oeste de la bahía de Chetumal, y 1,200 metros al este del camino que conduce de Payo Obispo a Santa Cruz Chico. De aquella ciudad dista 14 kilmetros al noroeste. ${ }^{2}$

La capilla mencionada, que mira hacia el oeste, está construída con piedra de montículos prehispánicos. En medio del atrio y frente a la puerta existe uno de ellos.

Las dimensiones de la misma son: $20.10 \mathrm{~m}$. $\times 10.40 \mathrm{~m}$. El espesor de sus muros es por término medio $1.30 \mathrm{~m}$. Se compone de una capilla central abierta con una gran entrada rematada por un arco currespondiente a la bóveda de cañón, de $6.60 \mathrm{~m}$. de diámetro y dos aposentos laterales de $7.80 \mathrm{~m} . \times 4.65$, y $7.80 \mathrm{~m} . \times 3.60 \mathrm{~m}$., que debieron servir, respectivamente, como habitación del capellán y como sacristía, pues en tanto que aquél tiene puerta hacia el atrio, el otro la tiene hacia la capilla.

El techo de los tres compartimentos está derrumbado totalmente. El de la capilla fué bóveda de cañón. Los muros se conservan en pie, en regular estado, excepto los que miran al sur y oriente de la habitación que se han caído. (Por lo que parece, también los dos aposentos laterales tuvieron bóveda de cañón.)

Al centro de la capilla y de la sacristía hay dos grandes oquedades practicadas por un espiritista llamado Antonio Cocom. Este sacó en 1927,

2 Las capillas abiertas, independientes de las iglesias y con enramadas como techos, son un tipo de construcsión que sólo se ha visto en Yucatán. (Nota del arquitecto John Mac Andrew.) 


\section{EXPLOICION LIENTIFILA MEXILANA \\ - 1937 -}

[entros y Ciudades calanales vecinos a las Mayas del [entra de furntana Poo- De los nombres pstritos, solamente Tızımín.Valladolid y Pelo no desapare cieron después de la Euerra de lastas

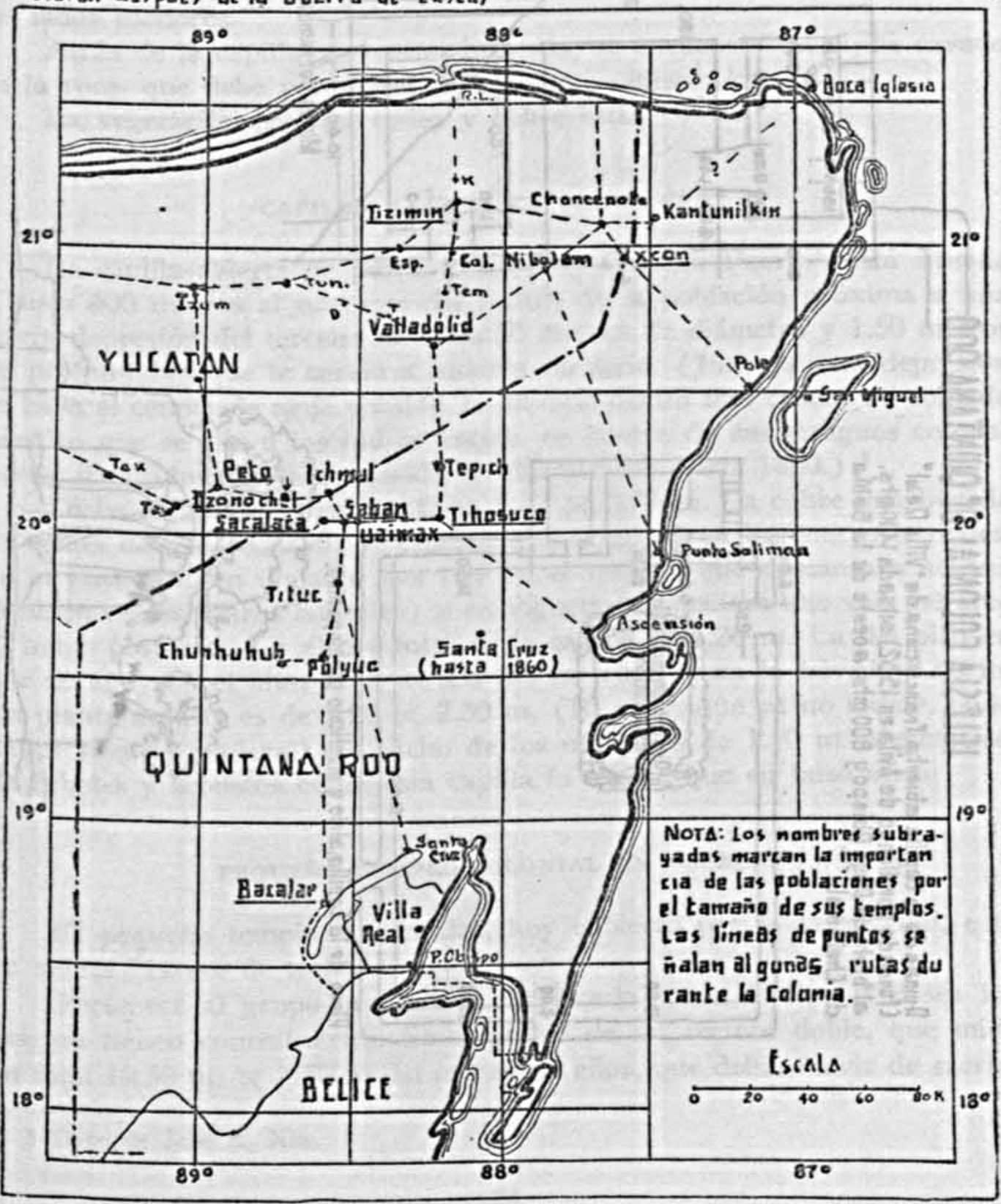




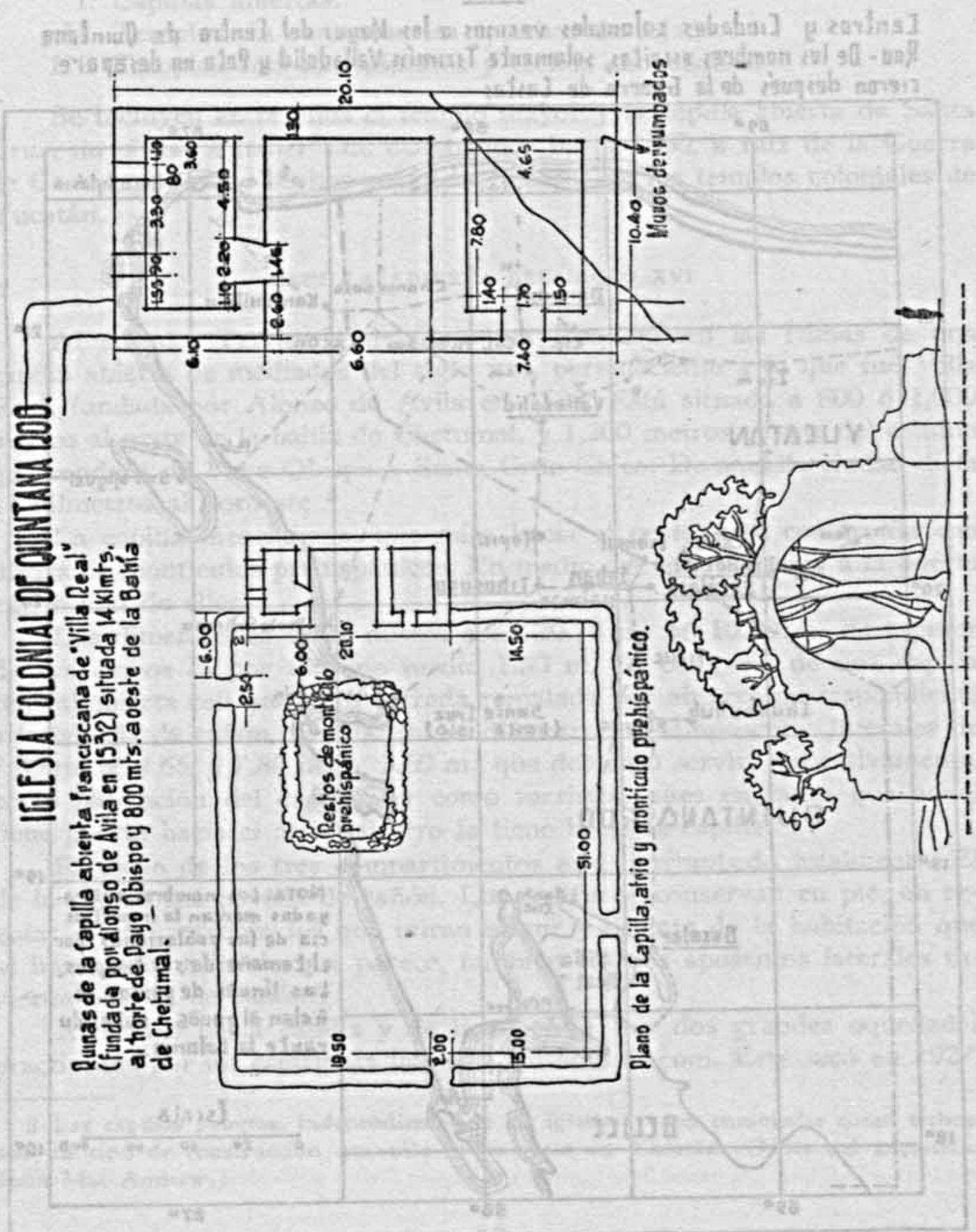


por indicación de su maestro, algunas cenizas que encontró en la capilla y las expuso al viento para que se purificaran; en la sacristía no halló nada.

Las dimensiones del atrio son: $51 \times 36.50 \mathrm{~m}$. Este tiene tres entradas: una al oeste, casi frente a la habitación, otra al norte, próxima a la sacristia y otra a la mitad de lado sur.

La capilla se encuentra hacia al noreste del mismo atrio, en uno de los laclos menores.

Atrás de la capilia y a corta distancia, se encuentra un aljibe cavado en la roca, que dehe pertenecer a la época prehispánica.

Ia vegetación boscosa rodea y cubre estas ruinas.

\section{CAPILLA ABIERTA EN SANTA CRUZ}

La capilla abierta de Santa Cruz (hoy Carrillo Puerto) está situada a unos 400 metros al noroeste del centro de la población proxina a una ligera depresión del terreno de unos 50 metros de diámetro y 1.50 metros de profundidad que le servía a manera de atrio. (Junto a esta depresión se halla el cenote de agua potable, en el cual plantó tres cruces un soldado mestizo que se alió a los indios mayas, en contra de sus antiguos compañeros, dando lugar a la fundación de Santa Cruz, hacia 1860.) 3

Dicha capilla mide en su planta $5.40 \times 3.75$ m. La cubre una bóveda de cañón de unos $0.30 \mathrm{~m}$. de espesor que se apoya en los muros iaterales, en el posterior, en un arco que hay en el frente (que descansa a su vez también en los muros laterales) y en viguetas de madera que van del arco al muro posterior. I a altura total de la capilla es $6.20 \mathrm{~m}$. La del piso en que se apoyaba el altar $1.15 \mathrm{~m}$. La clel interior, hasta la bóveda $4.60 \mathrm{~m}$. La planta de éste es de $3.20 \times 2.30 \mathrm{~m}$. (El altar, que ya no existe, pudo haber sido de madera.) El ancho de los muros es de $1.10 \mathrm{~m}$. Vegetación de árboles y arbustos cubre esta capilla lo mismo que sta falso atrio.

\section{PEQUEÑo TEMPLO COLONIAL EN BACALAR}

E1 pequeño templo de Bacalar, hoy cubierto por la vegetación, está en ruinas; carece de techo.

Pertenece al grupo que hemos clasificado como de tipo ir o sea los que no tienen contrafuertes. Se compone de un recinto doble, que mide en total $19.50 \mathrm{~m}$. $\times 7.30 \mathrm{~m}$. El menor de ellos, que debió servir de sacris-

3 Dato de José A. Xiu. 

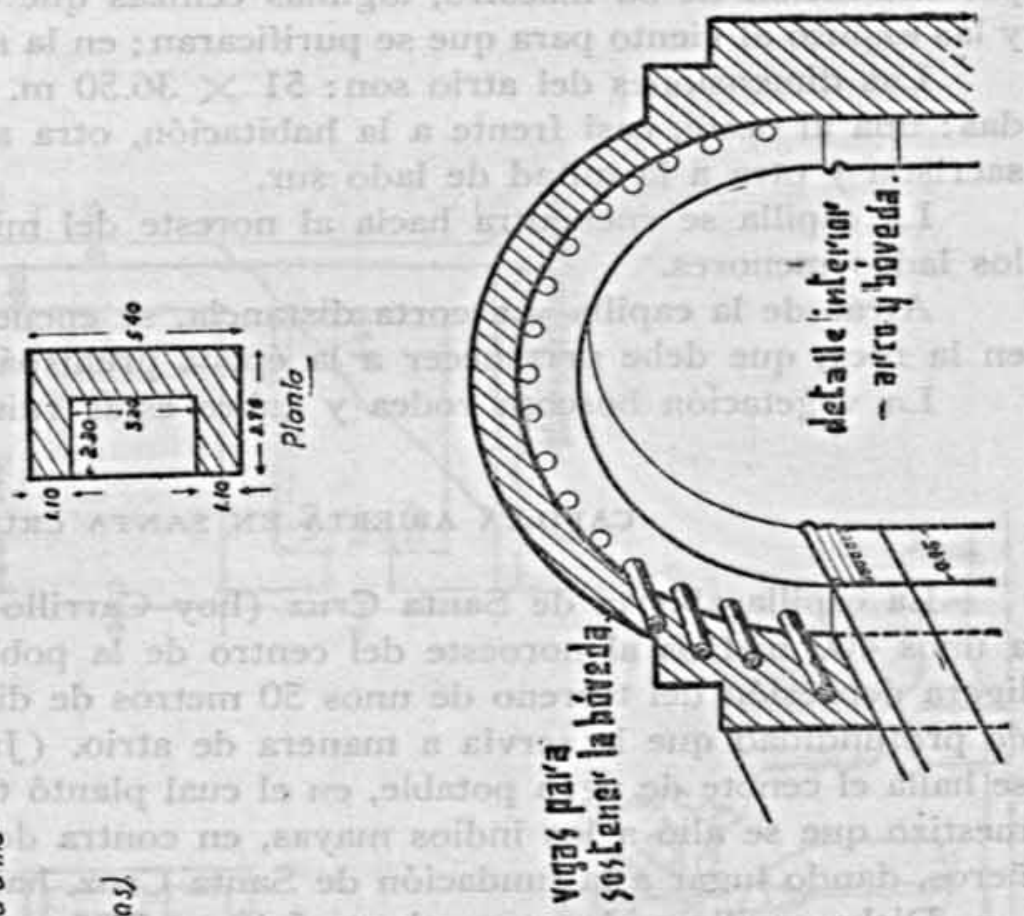

8:

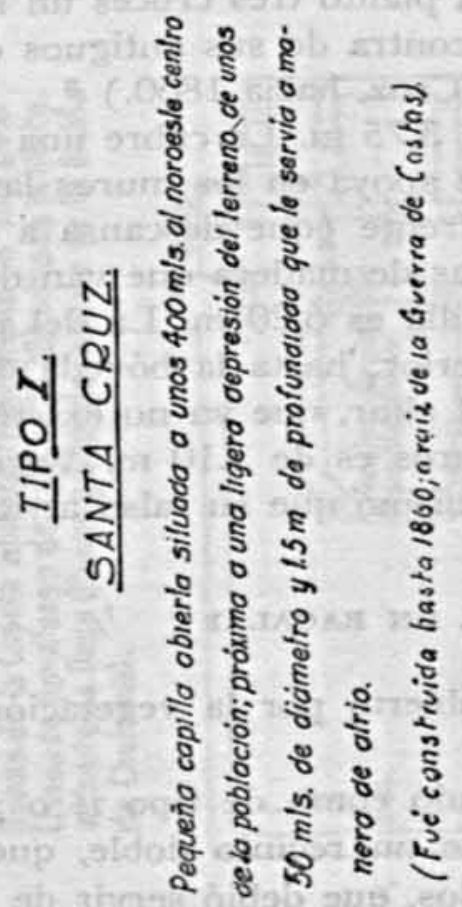




\section{TEMPLO COLONIAL EN DUIITANA ROO. - IIPD-II-}

Il templo pequeño de Bacalar.

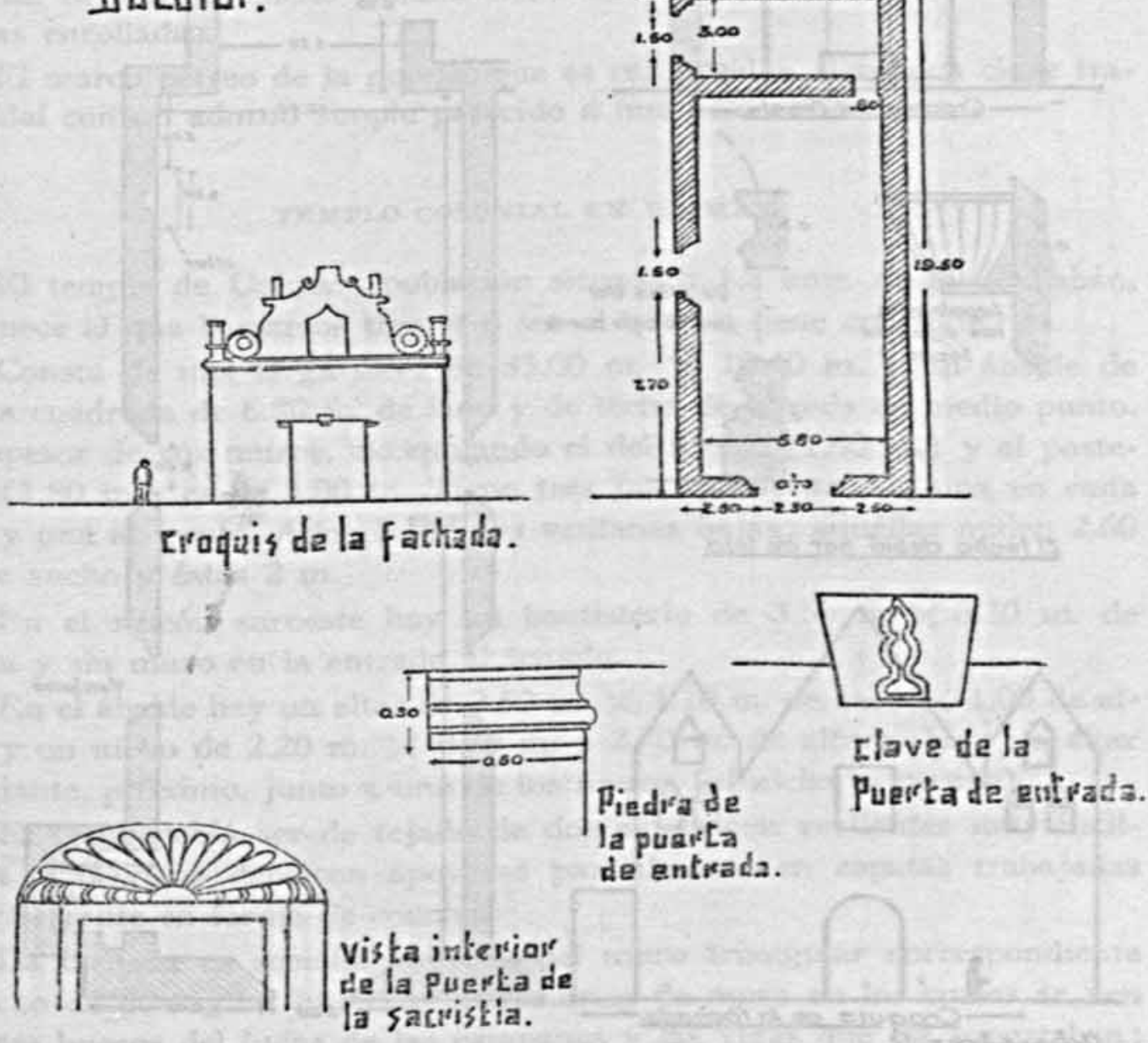




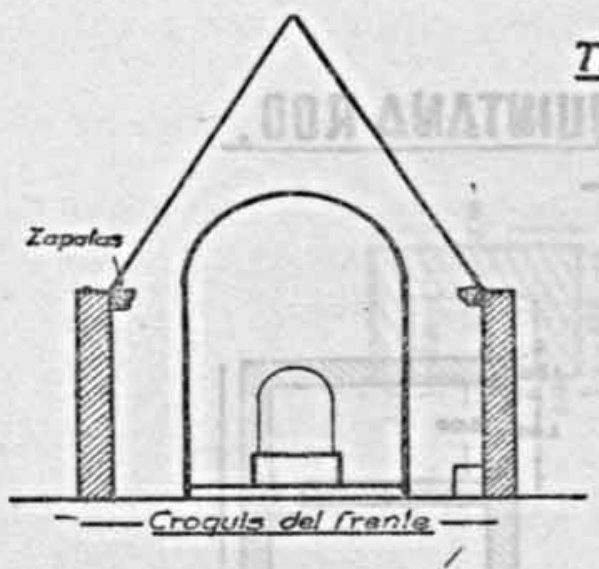

\section{TEMPLO COLONIAL EN OUINTANA BOO.}
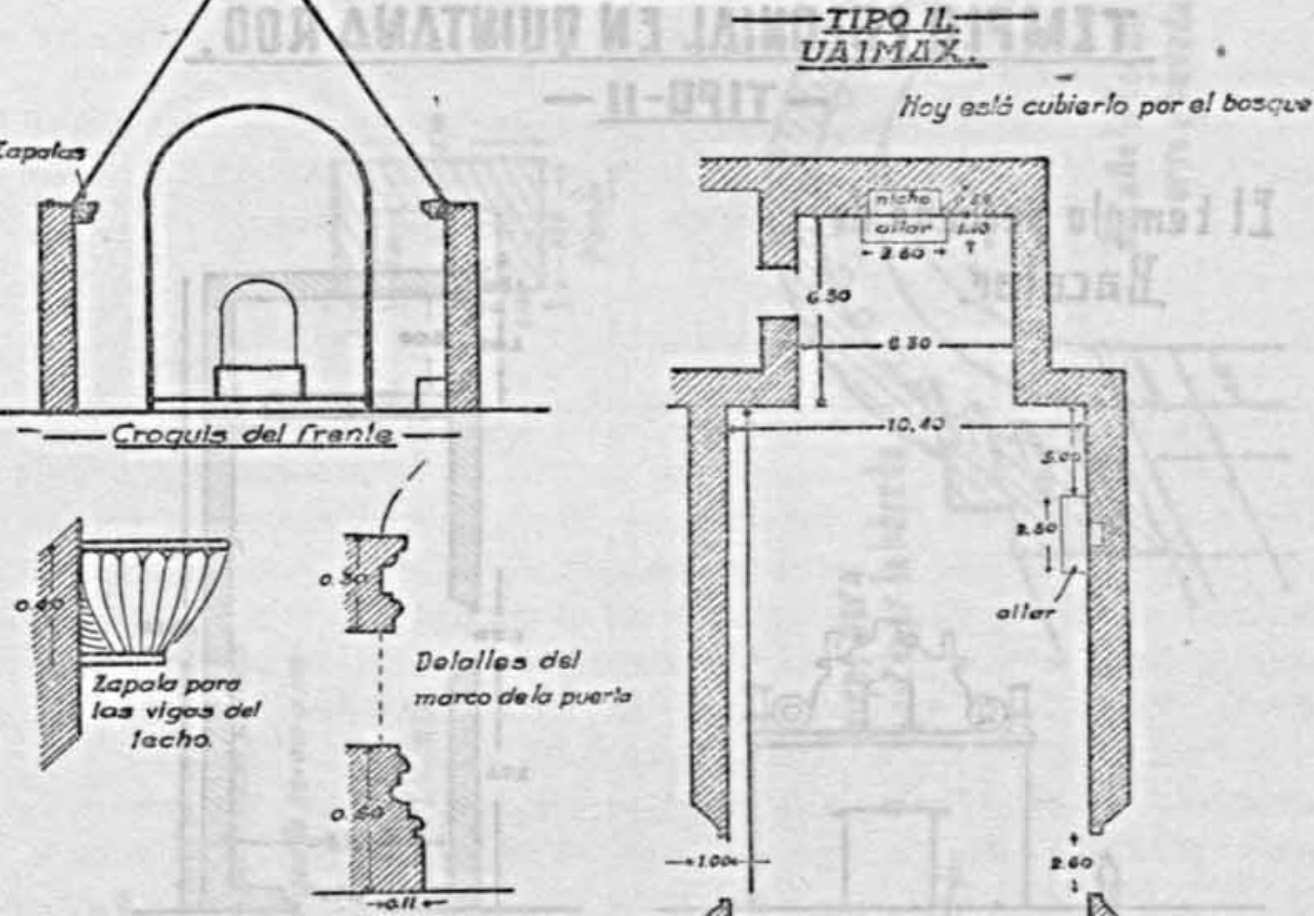

Ellecho debió ser de leia
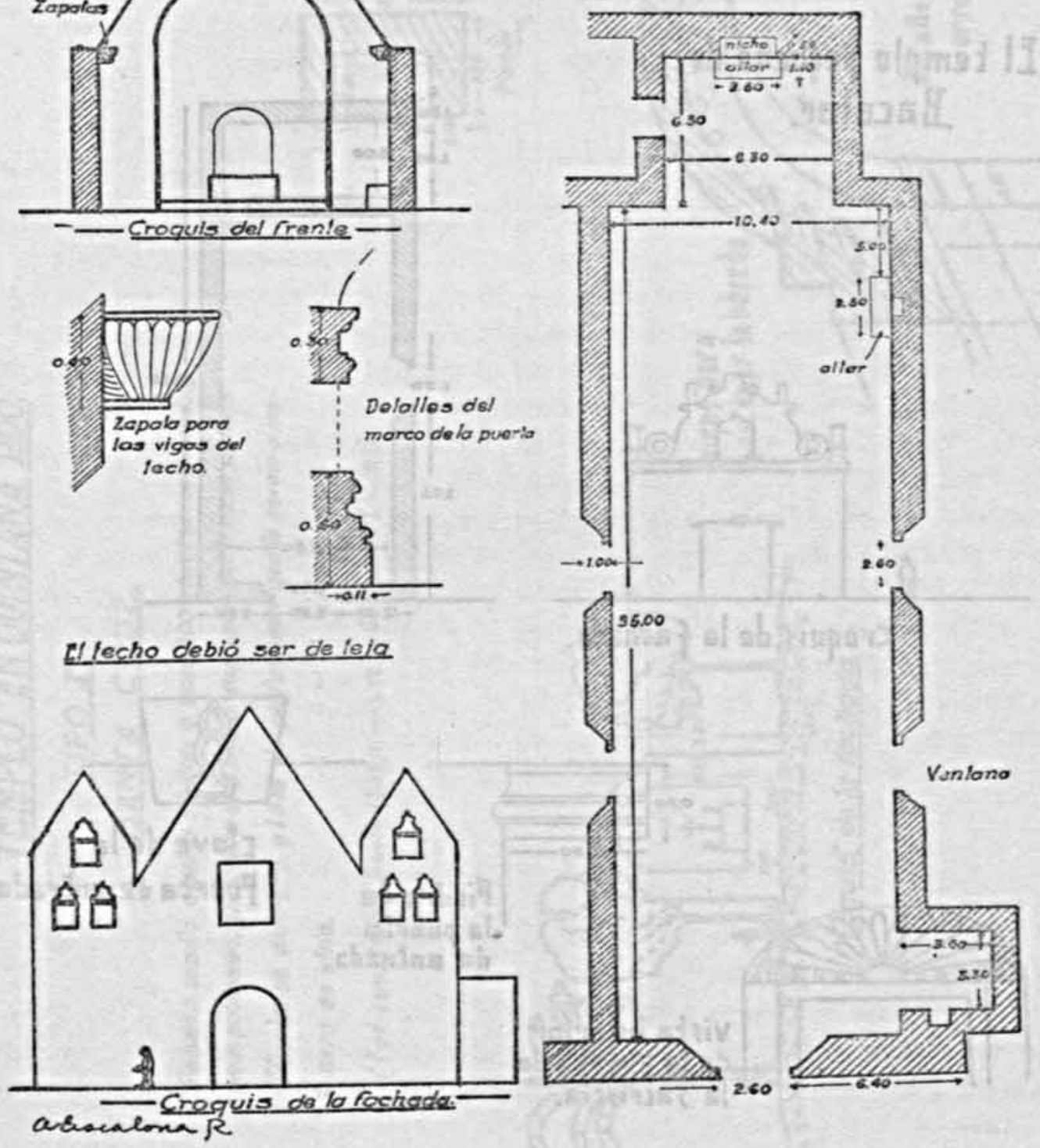
tía, está en la parte posterior y tiene $3 \mathrm{~m}$. de ancho interiormente; una puerta de $1.50 \mathrm{~m}$. de ancho da acceso a él y otra de $0.80 \mathrm{~m}$. lo comunica con la iglesia (el muro divisorio está muy destruido). Esta ocupa el resto de la construcción; tiene tres puertas hacia el exterior: una de cada lado (la del sur está clausurada); la del frente mide $2.30 \mathrm{~m}$, y las otras $1.50 \mathrm{~m}$. El ancho de los muros es $0.75 \mathrm{~m}$.

L.a puerta de la sacristía tiene en la parte alta un adorno en forma de concha hecha de estuco.

La fachacla tiene un remate para campanario que con la cruz (hoy perdida) debió tener unos $4.50 \mathrm{~m}$. de alto. El muro tiene más o menos $5.50 \mathrm{~m}$. de altura. Dicho remate tiene un perfil que recuerda el cle las esteras enrollarias.

El marco pétreo de la puerta, que es rectangular, tiene una clave trapezoidal con un adorno simple parecido a una vela ardiendo.

\section{TEMPLO COLONIAL EX UAIMAX}

El templo de Uaimax, población situada a $1.5 \mathrm{kms}$. de la de Sabán, pertenece al que llamamos tipo in o sea el que no tiene contrafuertes.

Consta de una larga nave de $35.00 \mathrm{~m}$. $\times 10.40 \mathrm{~m}$. y un ábside de planta cuadrada de $6.30 \mathrm{~m}$. de lado y de techo de bóveda de medio punto. El espesor de sus muros, exceptuando el del frente $(1.60 \mathrm{~m}$.) y el posterior $(1.80 \mathrm{~m}$.) es de $1.00 \mathrm{~m}$. Tiene tres puertas de acceso, una en cada lado y una al frente. Además de dos ventanas bajas; aquéllas miden 2.60 $\mathrm{m}$. de ancho y éstas $2 \mathrm{~m}$.

En el rincón suroeste hay un bautisterio de $3.50 \mathrm{~m} . \times 3.30 \mathrm{~m}$. de planta $y \sin$ muro en la entrada al templo.

En el ábside hay un altar de $2.50 \mathrm{~m} . \times 1.10 \mathrm{~m}$. de base $\times 1.00 \mathrm{de}$ altura y un nicho de $2.20 \mathrm{~m}$. $\times 0.80 \mathrm{~m}$. y $2.70 \mathrm{~m}$. de altura. Hay un altar semejante, próximo, junto a uno de los muros (el nicho es menor).

El techo debió ser de tejado de dos aguas con vertientes muy inclinadas. Las vigas debieron apoyarse parcialmente en zapatas trabajadas exteriormente en forma de concha.

La fachada es sencilla, además del muro triangular correspondiente al techo de dos aguas hay dos campanarios de muro en los cuales se ven los tres huecos del lugar de las campanas y las vigas que las soportaban; la silueta de ellos es la de un rectángulo en la parte inferior y de dos a 


\section{TEMPLO COLONIAL EN OUINTANA ROO.}

- TIPO III-

Iglesia Mayor de Bacalar.
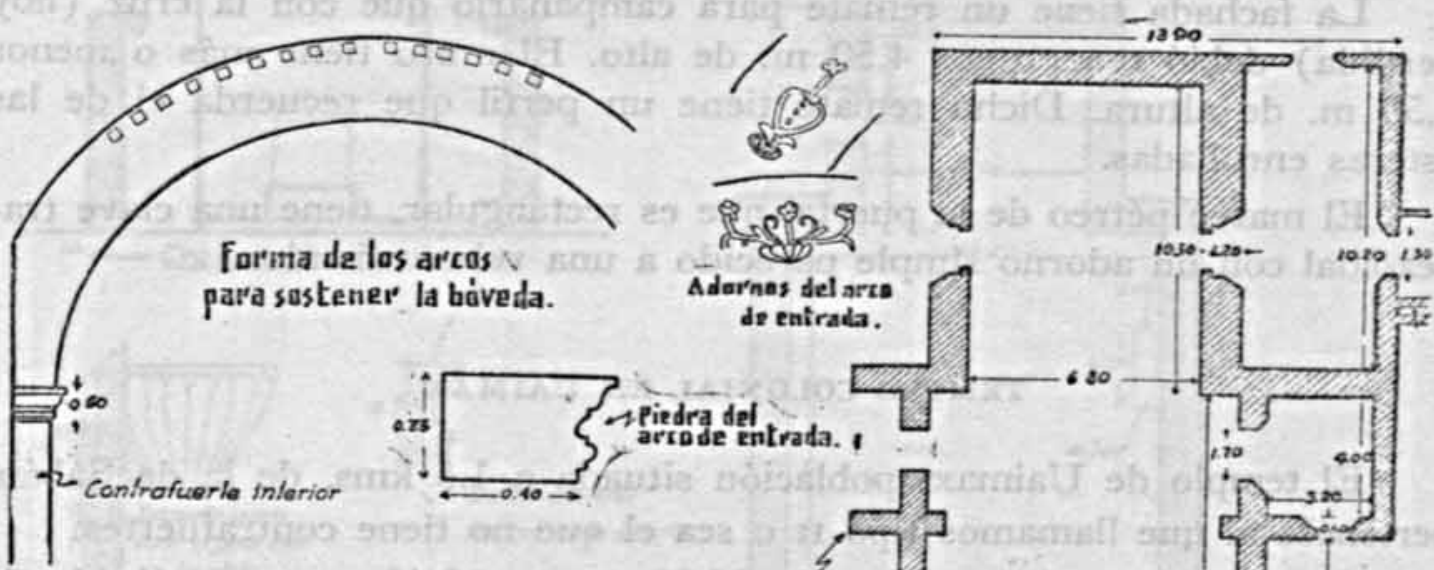

para sastener la báveda.

Adar'nas del arto de entrada.

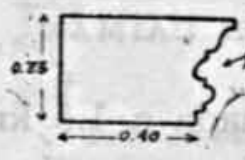

Ipiedra del

arrode entrada.
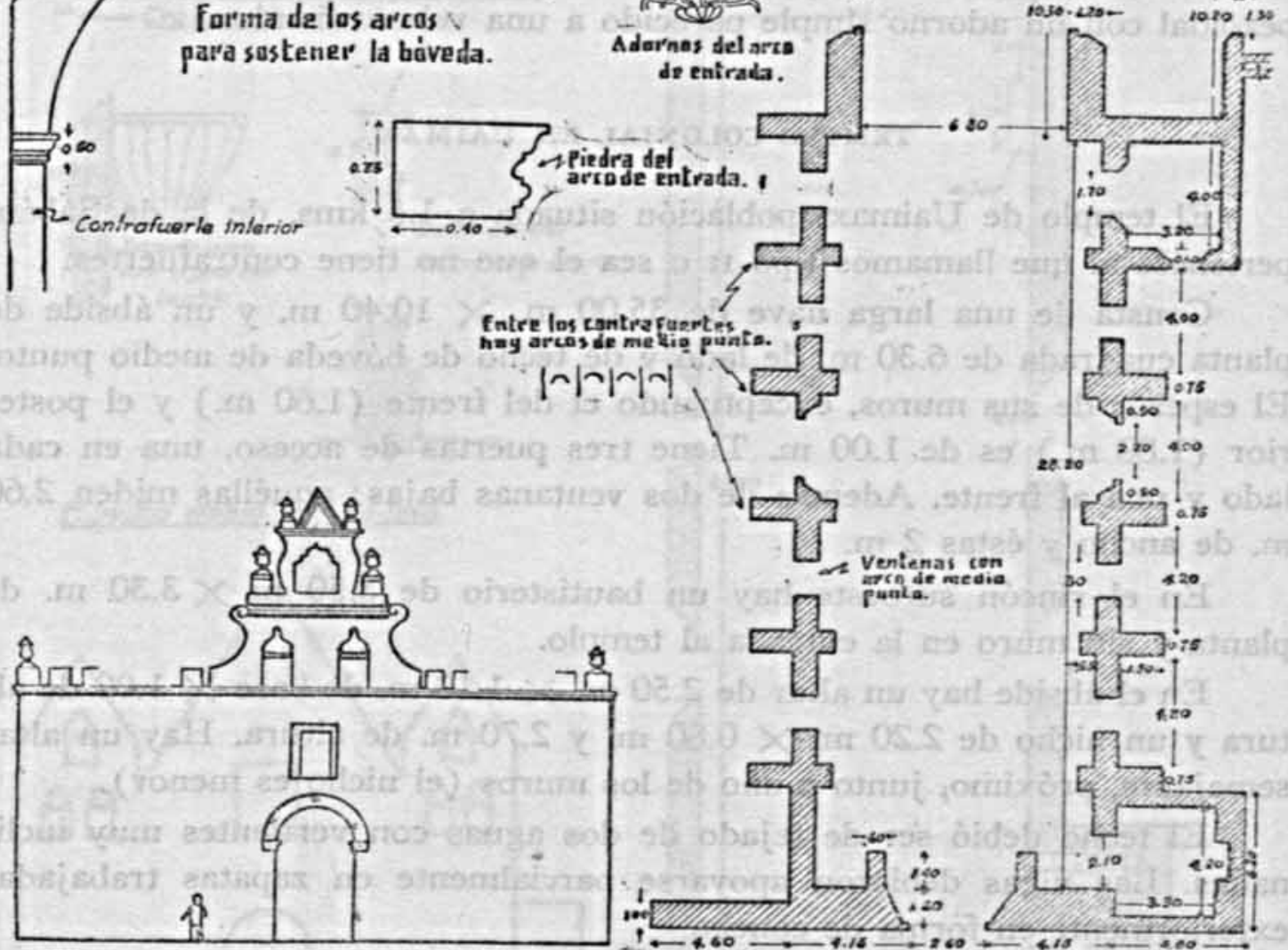

foter los cantra fusertes

$\operatorname{|n|\sim |\gamma |}$

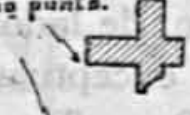

,

[raquis dé la fathada.

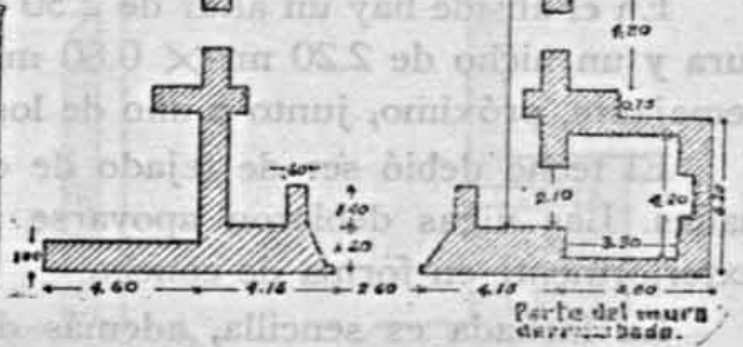


manera de ondas en la superior. Arriba de la puerta de entrada hay una ventana rectangular. Una iglesia semejante a ésta hay en Sacalaca (Quintana Roo) y otra en Dzonochel (Yucatán).

\section{TEMPLO COLONIAL EN BACALAR}

E1 templo mayor de Bacalar está en la población de este nombre, destruída durante la Guerra de Castas. Recientemente algunos componentes de la Expedición Cientifica Mexicana le quitaron varios de los árboles que impedian su mejor conocimiento.

Pertenece al tipo que llamamos Irr, es decir, al de los templos que tienen contrafuertes $y$ que debieron llevar bóveda.

Sus dimensiones interiores, sin contar el ábside, son $28.20 \mathrm{~m} . \times 9.30$ m. y las de éste $10.30 \mathrm{~m}$. $\times 6.80 \mathrm{~m}$.

De los seis contrafuertes de cada lado, tres están situados de uno y otro lado de las puertas laterales; miden $1.50 \mathrm{~m}$. $\times 0.75 \mathrm{~m}$. de base $\mathrm{y}$ están separados $4.20 \mathrm{~m}$. los de un lado de la puerta y $4 \mathrm{~m}$. los del otro. Entre dos de éstos se construyó una pequeña capilla de $3.20 \mathrm{~m}$. $\times 4 \mathrm{~m}$. junto a la sacristia. A los contrafuertes corresponden interiormente pilastras de $0.75 \mathrm{~m}$. $\times 0.55 \mathrm{~m}$. para soportar los arcos de la bóveda (de cañón). El espesor de los muros es de $0.75 \mathrm{~m}$. excepto en la fachada (1.50) y el ábside $(1.20 \mathrm{~m}$.). En la esquina suroeste está el bautiserio, que mide por dentro $4.20 \mathrm{~m}$. $\times 3.30 \mathrm{~m}$. y su puerta $2.10 \mathrm{~m}$. La sacristía está comunicada con el ábside por una puerta; sus medidas interiores son $10.20 \mathrm{~m}$. $\times 4 \mathrm{~m}$; t tiene otras dos puertas hacia el exterior. 4

Entre los contrafuertes (que exteriormente se refuerzan con arcos de medio punto colocados entre uno y otro) hay ventanas con arcos de medio punto de $1.80 \mathrm{~m}$. de alto y $1.30 \mathrm{~m}$. de ancho.

La fachada prolongada hacia un lado para lograr la simetría con el bautisterio es un gran rectángulo en su parte inferior y un campanario de muro en la superior, distribuyendo éste en dos porciones: en la de abajo hay dos huecos correspondientes al lugar donde debieron estar las campanas y en ei de arriba otro con el mismo destino. La silueta de la de abajo recuerda dos tiras enroscadas y la de arriba una olla o vasija con su remate triangular.

4 Quizá el techo debió ser de madera, pues la ligereza de los muros impide, según parece, la construcción de una bóveda de piedra. (Nota de J. McA.) 
TEMPLO-TOLQWLALER Q.RQD - TIPA III -

\section{SABAN}
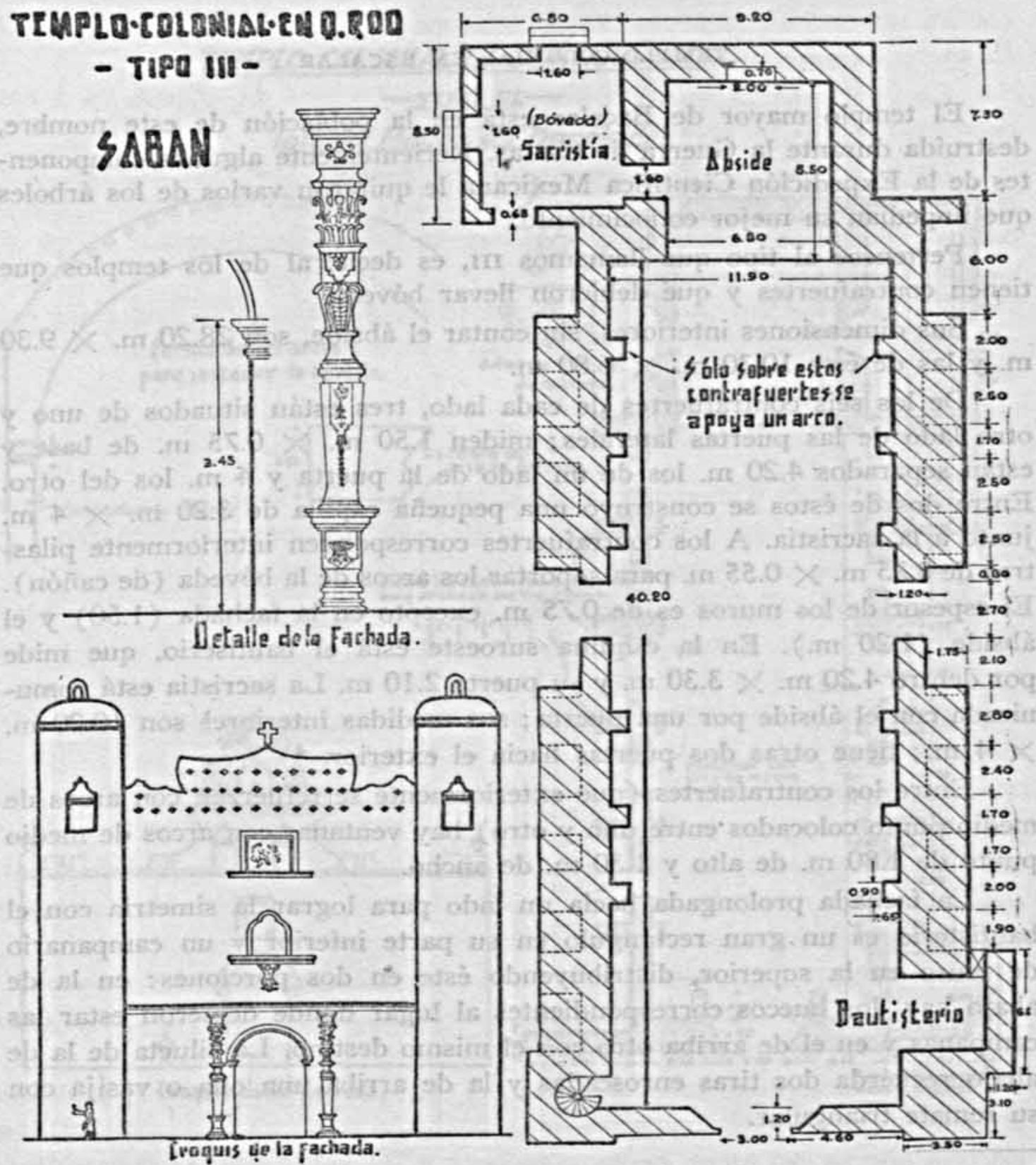
IJay, además, sobre la parte recta del muro seis cubos a cada lado. En los de los extremos hay dos a manera de jarrones decorativos; jarrones iguales a los que de dos en dos completan el adorno o porción superior de la fachada.

En el arco de la puerta de entrada hay tres adornos florales sencillos.

TEMPLO COLONIAL EN SABAN

El templo de Sahan, población del norte de Quintana Roo que fué destruida en la Guerra de Castas y que ha ido volviendo a vivir de cuatro años a esta parte, está situado al oriente de la gran plaza principal. Está aisiado. Pertenece al tipo que hemos llamado 111 o sea los que tienen contrafuertes y debieron soportar bóvedas. Este edificio da la impresión de no haber sido concluido o quizá habiéndosele terminado una vez fué preciso reedificarlo para darle mayor solidez; para esto último se reforzaron los contrafuertes rellenando los espacios intermedios. Hoy no existe más que un arco en pie que iba a ayudar a sostener la nueva bóveda y es el que está próximo al ábside.

I a iglesia es una de las más grandes de Quintana Roo; tiene seis contrafuertes a cada lado, tres a uno y otro lado de las puertas laterales; el de enmedio de estos tres mide $1.70 \mathrm{~m}$. de ancho, los otros miden $2 \mathrm{~m}$., 2.50 y $2.80 \mathrm{~m}$. A los contrafuertes corresponden interiomente pilastras para los arcos de $0.90 \mathrm{~m}$. $\times 0.65 \mathrm{~m}$. de base. La distancia entre los contrafuertes es de 1.70 a $2.50 \mathrm{~m}$. El espesor de éstos es de $1.75 \mathrm{mi}$. Las esquinas de las fachadas son más gruesas $(4.30 \mathrm{~m}$. $\times 3.50 \mathrm{~m}$.). Las puertas laterales tienen $255 \mathrm{~m}$. de ancho y la del frente $3 \mathrm{~m}$.

En el rincón suroeste hay un bautisterio de $3.50 \mathrm{~m} . \times 3.70 \mathrm{~m}$. En la esquina noroeste está la escalera de caracol que da acceso a las torres y antes también a la azotea; tiene $2 \mathrm{~m}$. de diámetro. Junto al ábside está la sactistia que aún conserva su bóveda, tiene tres puertas hacia el exterior y otra hacia el ábside de $1.60 \mathrm{~m}$. de ancho. Mide interiormente $6 \times 7 \mathrm{~m}$.

En la fachada se destacan las torres que son muy sencillas; están rematadas por unas bóvedas bajas; tienen cuatro ventanas, una hacia cada punto cardinal en las que debieron estar las campanas, su silueta es la de un rectángulo abajo y dos a manera de ondas arriba. Por encima de lo que fué la bóveda hay un muro con silueta de corona y con varias filas de figuras caladas. Abajo de él hay un bajorrelieve que representa a San Pedro con el gallo de la pasión, bastante bien trabajado. A su vez tiene 


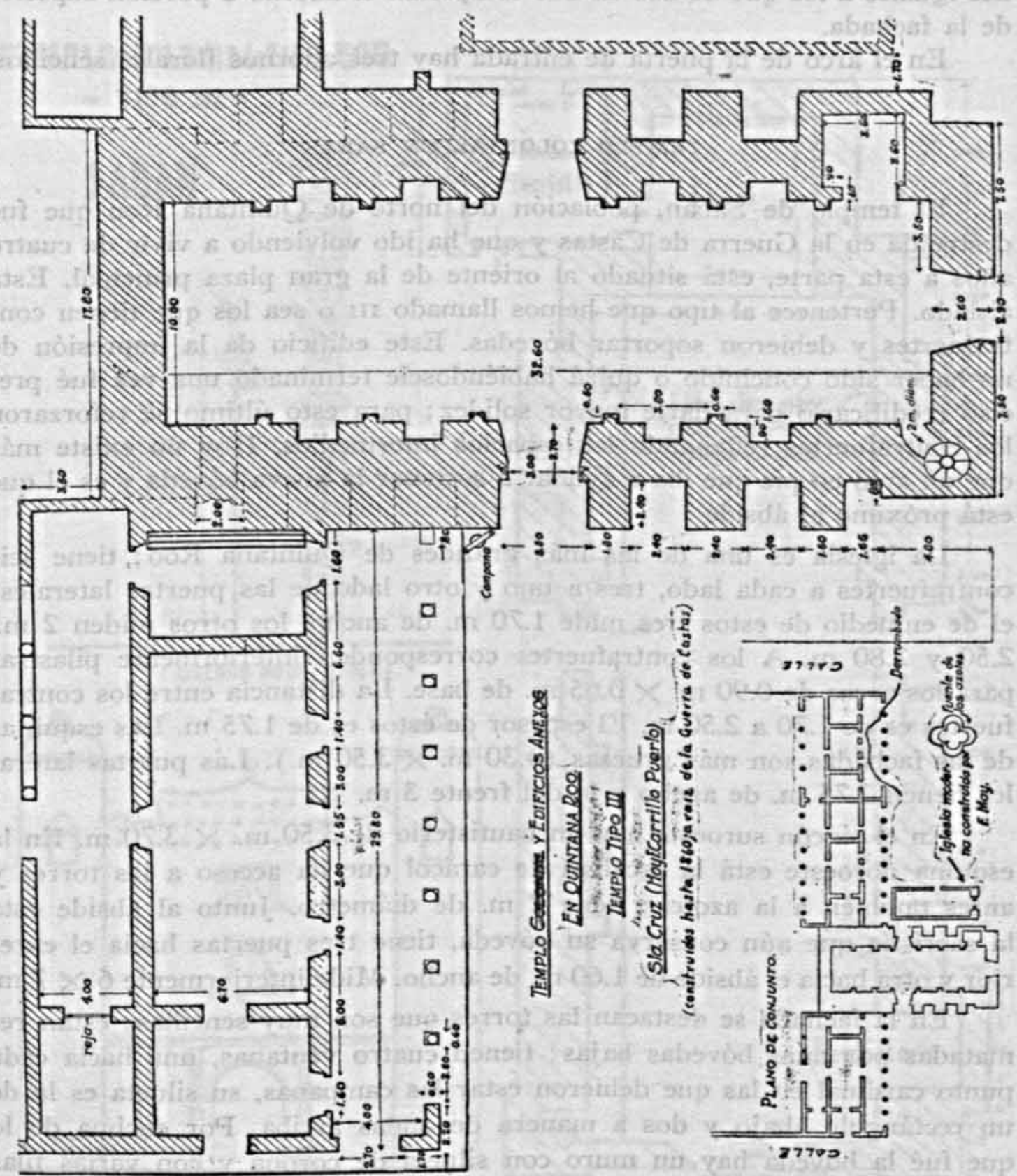


DOI: http://dx.doi.org/10.22201/iie.18703062e.1943.10.342
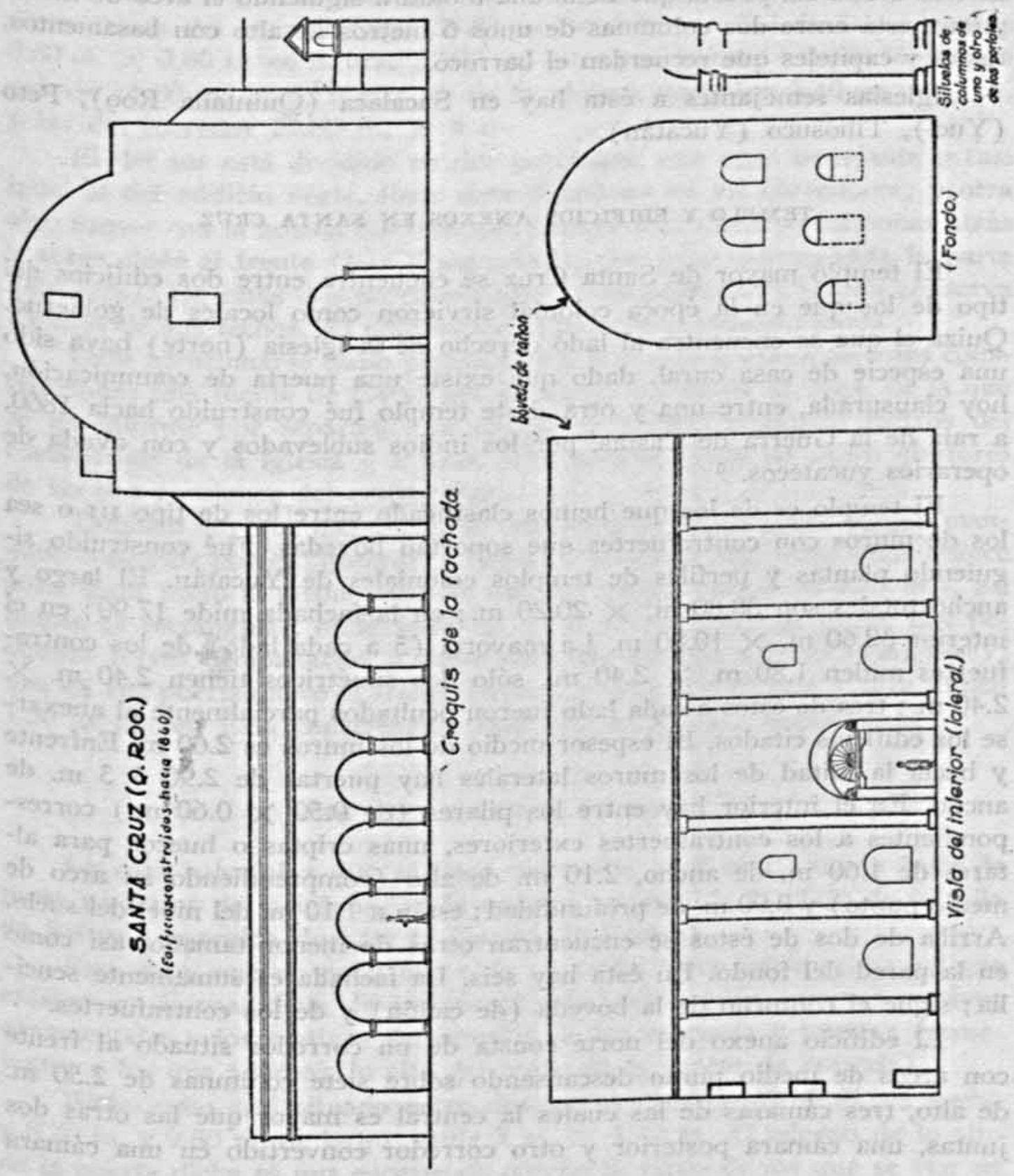
abajo una ventana que pudo cortesponder al coro con una larga cornisa inferior sostenida aparentemente por un ángel; lo alto de la ventana es de tres arcos. La puerta que tiene una moldura siguiendo el arco de medio punto, está entre dos collimnas de unos 6 metros de alto con basamentos, fustes y capiteles que recuerdan el barroco.

Iglesias semejantes a ésta hay en Sacalaca (Quintana Roo), Peto (Yuc.), Tihosuco (Yucatán).

\section{TEMPLO Y EDIERCIOS ANEXOS EN SANTA CRUZ}

El templo mayor de Santa Cruz se encuentra entre dos edificios del tipo de los que en la época colonial sirvieron como locales de gobierno. Quizá el que se encuentra al lado derecho de la jglesia (norte) haya sido una especie de casa cural, dado que existe una puerta de comunicación, hoy clausurada, entre una y otra. Este templo fué construído hacia 1860 , a raíz de la Guerra de Castas, por los indios sublevados y con ayuda de operarios yucatecos. "

El templo es de los que hemos clasificado entre los de tipo in o sea los de muros con contrafuertes que soportan bóvedas. Fué construído siguiendo plantas y perfiles de templos coloniales de Yucatán. El largo y ancho totales son $38.80 \mathrm{~m}$. $\times 20.20 \mathrm{~m}$; ; en la fachada mide 17.90 ; en el interior $32.60 \mathrm{~m}$. $\times 10.80 \mathrm{~m}$. La mayoría (5 a cada lado) de los contrafuertes miden $1.80 \mathrm{~m}$. $\times 2.40 \mathrm{~m}$., sólo dos simétricos tienen $2.40 \mathrm{~m}$. $\times$ $2.40 \mathrm{~m}$.; tres de éstos a cada lado fueron ocultados patcialmente al anexarse los edificios citados. El espesor medio de los muros es $2.60 \mathrm{~m}$. Enfrente y hacia la mitad de los muros laterales hay puertas de 2.90 ó $3 \mathrm{~m}$. de ancho. En el interior hay entre los pilares (de $0.50 \times 0.60 \mathrm{~m}$.) correspondientes a los contrafuertes exteriores, unas criptas o huecos para altares de $1.60 \mathrm{~m}$. de ancho, $2.10 \mathrm{~m}$. de alto (comprendiendo su arco de medio punto) y $0.90 \mathrm{~m}$. de profundidad; están a $1.10 \mathrm{~m}$. del nivel del suelo. Arriba de dos de éstos se encuentran otras de menor tamaño, así como en la pared del fondo. En ésta hay seis. La fachada es sumamente sencilla; sigue el contorno de la bóveda (de canión) y de los contrafuertes.

E1 edificio anexo del norte consta de un corredor situado al frente con arcos de medio punto descansando sobre siete columnas de $2.50 \mathrm{~m}$. de alto, tres cámaras de las cuales la central es mayor que las otras dos juntas, una cámara posterior y otro corredor convertido en una cámara

5 Dato de José A. Xiu. 
abierta debido a que algunas de sus columnas fueron reemplazadas por muros y a que entre las tres restantes se pusieron muros de $1.5 \mathrm{~m}$. de alto; entre éste y la cámara hay una antigua reja de hierso forjado. Las dimensiones del corredor son $29.80 \mathrm{~m}$. $\times 4.60 \mathrm{~m}$; las de las columnas $0.60 \mathrm{~m}$. $\times 0.60 \mathrm{~m}$. en la base $(2.80 \mathrm{~m}$. entre una y otra $)$; las de la cámara grande $16.80 \mathrm{~m} . \times 6.70 \mathrm{~m}$; las de la cámara posterior $5.40 \mathrm{~m} . \times 4 \mathrm{~m}$. $y$ las del corredor $23.80 \mathrm{~m} . \times 4 \mathrm{~m}$.

El del sur está dividido en dos porciones, una muy semejante o casi igual al del edificio norte, tiene siete columnas en los corredores; y otra algo menor con la misma distribución, aunque con sólo tres colunnas atrás y acaso cinco al frente (hoy desaparecidas por estar derrumbada la parte delantera). De estas dos porciones sólo la inmediata a la iglesia conserva algunos de sus techos. Al edificio norte se le han reparado todos.

Debe mencionarse como perteneciente a la misma época de estas construcciones una fuente de plata "ojo de buey" en forma de cruz, de la que se da informe por separado; se encuentra a unos veintiséis metros del costado sur de la iglesia y a unos once metros frente al muro divisorio de las dos porciones del edificio sur.

También hay que mencionar la cxistencia de un pequeño templo mandado construir por el "general" indigena Francisco May hace unos quince años. Está junto al mismo costado sur del templo mayor (a $1.70 \mathrm{~m}$.). Su planta es rectangular, mide $18.30 \mathrm{~m}$. $\times 7.20 \mathrm{~m}$; ; tiene al frente dos pequeñas torres campanarios $y$ entre ellas un frontón (pared triangular); una de sus puertas abte al frente (oeste) y otra al sur; una y otra mider 1.50 de ancho. Esta construcción está hoy dedicada a escuela.

\section{UNA CASA COLONIAL FN SABAN}

La casa colonial a que se hace referencia aquí está situada hacia la parte posterior de la iglesia, en la esquina noreste de la plaza de la villa de Saban (destruida durante la Guerra de Castas).

Esta casa, que no es la única de su estilo, pues son muchas las que existen ex ruinas, tiene de interés el cubo del zaguán por sus motivos otnatnentales y los motivos del interior de las ventanas y puertas (semejantes a los que adornan lo alto del lugar de la puerta de entrada).

Dicho cubo está situado entre dos largas cámaras de $5 \mathrm{~m}$. de ancho y $8.20 \mathrm{~m}$. y $9.80 \mathrm{~m}$. de largo; mide $5 \mathrm{~m}$. $\times 4.70 \mathrm{~m}$. El adorno de lo alto de la puerta dicha es una especie de concha al estilo de las que se ven en Yucatán y Campeche, tiene unos $0.70 \mathrm{~m}$. de altura y 3.15 de ancho. El 

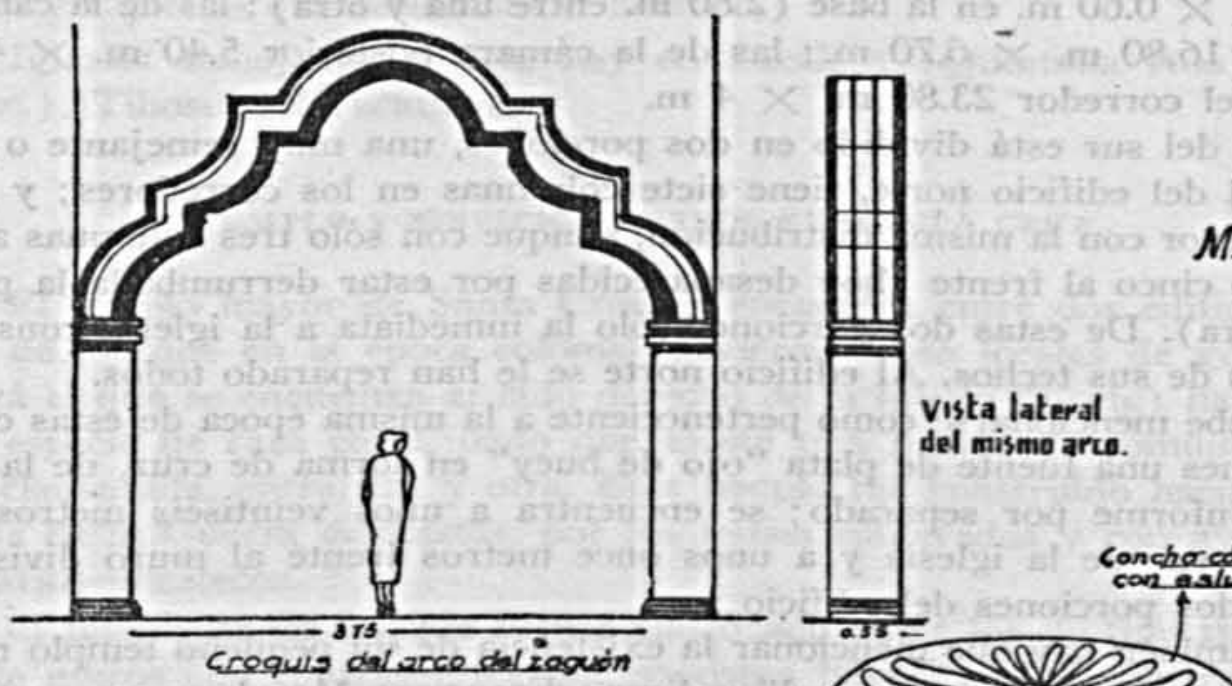

$M$.

Iasa Iolomiac en Qumirama Rog.

siluada en la esquina nor'sste de la plaza mayar de la Villa de Saban (hoy en ruinas) 1933.

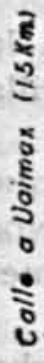

\section{SABAN.}
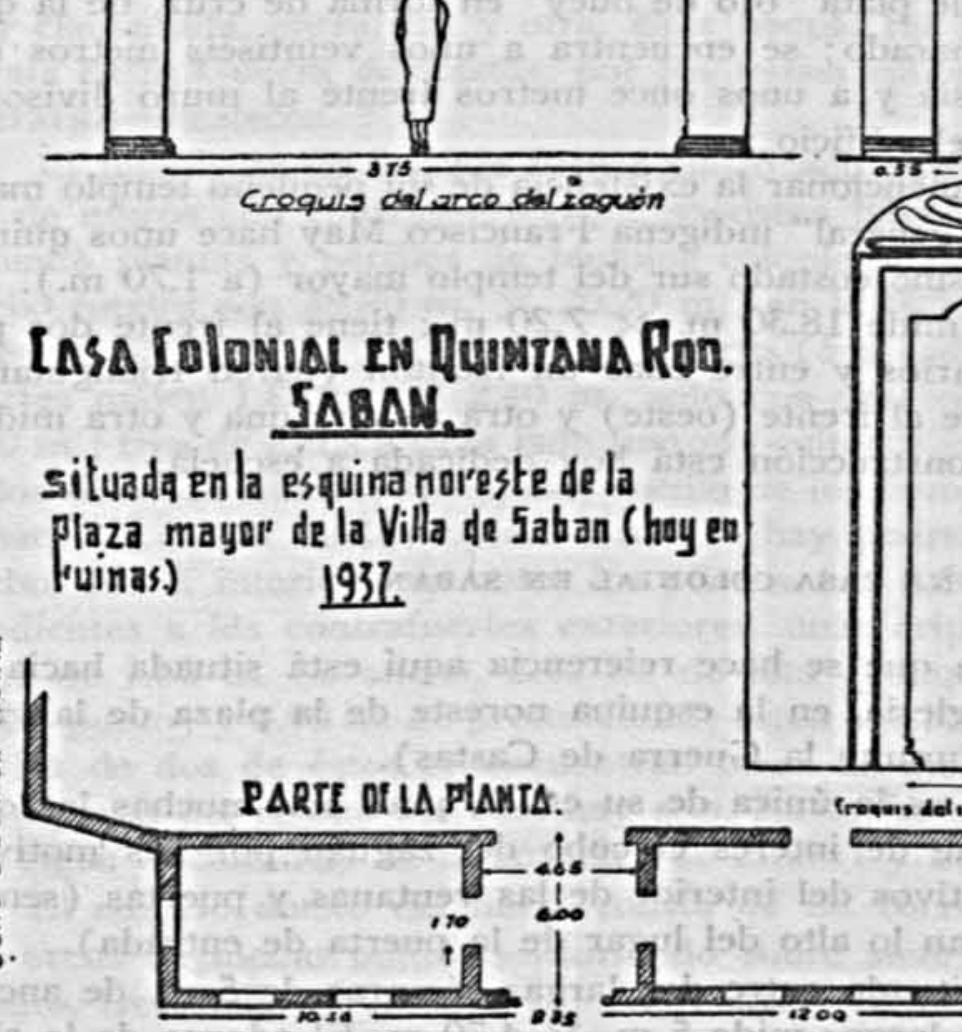

del mismo arce.
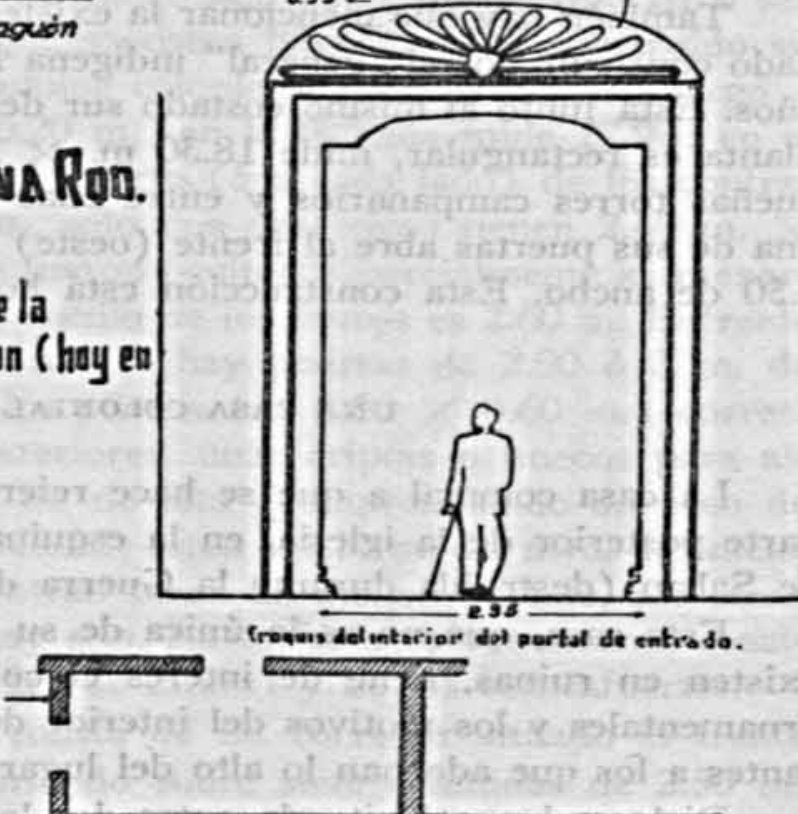

calle haria la espalda de la iglesia. 
marco pétreo de la misma puerta tiene un perfil curvo de $0.25 \mathrm{~m}$. de alto. El arco que da acceso al patio tiene un contorno interior que recuerda un medio "ojo de buey" de los cuatro semicírculos unidos a un gran cuadro central con la característica, en este caso, que dichas esquinas del cuadro a su vez recortadas por cuartos de circulo colocados en sentido contrario a los otros. El ancho del arco es de $0.55 \mathrm{~m}$. y su altura interior $4.10 \mathrm{~m}$., aproximadamente. Una moldura de $0.40 \mathrm{~m}$. de ancho sigue el contorno del arco.

\section{FUENTE EN SANTA CRUZ}

La fuente de la plaza central de Santa Cruz (hoy C. Puerto), está situada, según se indica en otro informe, a unos 26 metros del costado sur del templo mayor (o sea a unos $12 \mathrm{~m}$, del mandado construir por el "general" F. May) y a unos 11 metros del edificio anexo sur del dicho templo mayor. Fué construida hacia 1860.

Su planta general es de las llamadas de "ojo de buey" en cruz o sea cuatro porciones de círculo (en este caso algo más de la mitad) unidos para formar una cruz; dejando pues un cuadro en el centro al tunirse los extremos de las partes de circunferencia correspondientes a dichas por-
ciones de circulos.

Descansa sobre una plataforma de unos $0.30 \mathrm{~m}$. de aito y de una planta como la fuente misma de $8.10 \mathrm{~m}$. de extremo a extremo. El borde de la fuente tiene $0.40 \mathrm{~m}$. de ancho y de extremo a extremo de éste hay $5.90 \mathrm{~m}$. El cuadro central tiene $2.20 \mathrm{~m}$. de lado y el radio de cada círculo es de $1.20 \mathrm{~m}$. La altura de la fuente es $0.80 \mathrm{~m}$. Debido a su gálibo exterior en forma de 5 sobresale del borde hacia todos lados $0.15 \mathrm{~m}$. (el interior es recto, perpendicular al suelo).

\section{POZO DE TYPO COLONIAL EN RANTUNILKIN}

La fuente del pueblo de Kantunilkin puede considerarse como de tipo colonial yucateco. Debe haber sido construida en el siglo xvir cuando este poblado dependia de la ex ciudad de Xcan (una de las avanzadas más importantes del coloniaje al oriente de Yucatán), que se halla a unas 9 leguas al suoreste.

Kantunilkin fué destruido casi a fines del siglo pasado por los indios sublevados cuando sus pobladores indigenas y mestizos se sometieron voluntariamente al gobierno de Yucatán (sin que éste les prestara ayuda); 
DOI: http://dx.doi.org/10.22201/iie.18703062e.1943.10.342

\section{FUENTE EN OUINTANAROO Sta.Cruz}
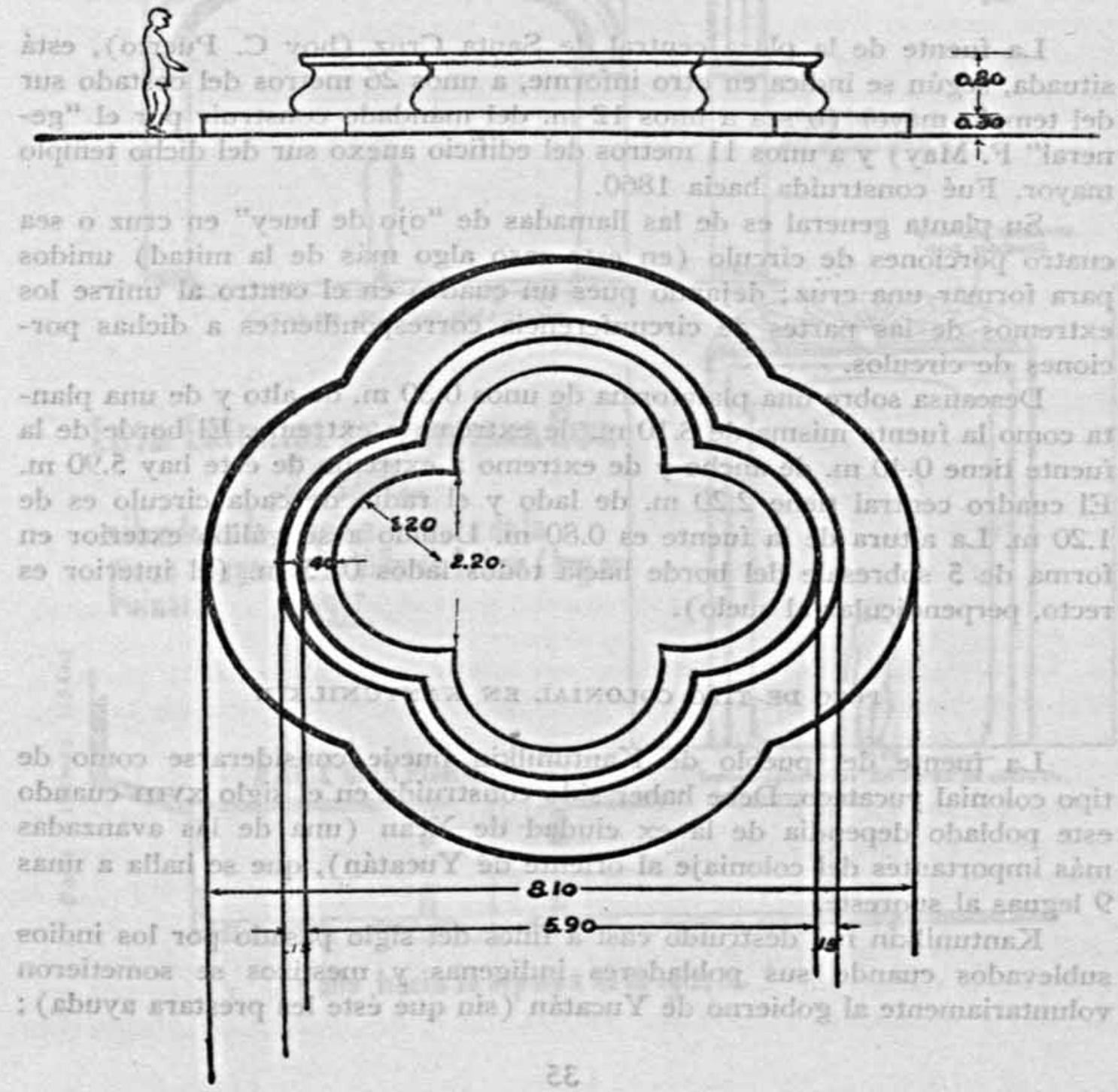


\section{POZO DE TIPO COLONIAL DEL PUEBLO DE KANTUNILKIN, Q DOD}
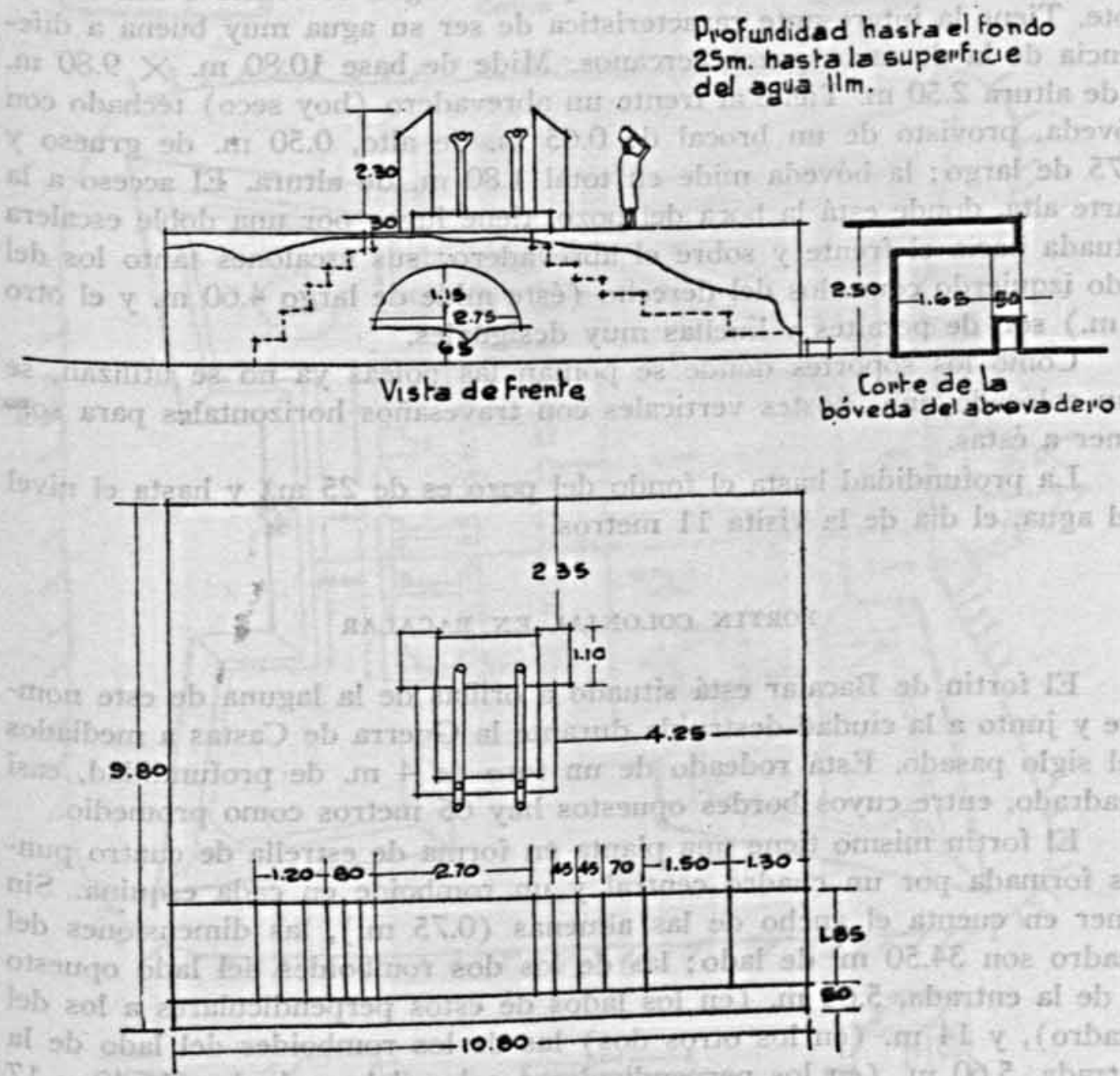
aquellos indios consideraron una traición semejante hecho $\mathbf{y}$ por eso destruyeron el pueblo. Hoy ha vuelto a surgir y cuenta ya con algunos cientos de habitantes.

Como construcciones de interés, además de la fuente, debe señalarse la casa en reconstrucción que ocupa la Delegación de Gobierno, que debió ser una pequeña capilla y una casa hoy totalmente desaparecida hasta sus cimientos, la cual estaba próxima a la anterior.

La fuente misma está sobre un pozo de agua corrieñte o sea un cenote. Tiene la interesante característica de ser su agua muy buena a diferencia de la de otros pozos cercanos. Mide de base $10.80 \mathrm{~m}$. $\times 9.80 \mathrm{~m}$. y de altura $2.50 \mathrm{~m}$. Tiene al frente un abrevadero (hoy seco) techado con bóveda, provisto de un brocal de $0.65 \mathrm{~m}$. de alto, $0.50 \mathrm{~m}$. de grueso y 2.75 de largo; la bóveda mide en total $1.80 \mathrm{~m}$. de altura. El acceso a la parte alta, donde está la boca del pozo, tiene lugar por una doble escalera situada hacia el frente y sobre el abrevadero; sus escalones tanto los del lado izquierdo como los del derecho (éste mide de largo $4.60 \mathrm{~m}$. y el otro $2 \mathrm{~m}$.) son de peraltes y huellas muy desiguales.

Como los soportes donde se ponian las poleas ya no se utilizan, se han colocado unos postes verticales con travesaños horizontales para sostener a éstas.

La profundidad hasta el fondo del pozo es de $25 \mathrm{~m}$., y hasta el nivel del agua, el dia de la visita 11 metros.

\section{FORTIN COLONIAL EN BACALAR}

El fortín de Bacalar está situado a orillas de la laguna de este nombre y junto a la ciudad destruída durante la Guerra de Castas a mediados del siglo pasado. Está rodeado de un foso de $4 \mathrm{~m}$. de profundidad, casi cuadrado, entre cuyos bordes opuestos hay 65 metros como promedio.

El fortín mismo tiene una planta en forma de estrella de cuatro puntas formada por un cuadro central y un romboide en cada esquina. Sin tener en cuenta el ancho de las almenas $(0.75 \mathrm{~m}$.), las dimensiones del cuadro son $34.50 \mathrm{~m}$. de lado; las de los dos romboides del lado opuesto al de la entrada, $5.60 \mathrm{~m}$. (en los lados de éstos perpendiculares a los del cuadro), y $14 \mathrm{~m}$. (en los otros dos) las de los romboides del lado de la entrada, $5.60 \mathrm{~m}$. (en los perpendiculares a los del cuadro) y 16.40 y 17 m. (en los otros dos). Los lados del cuadro libres (sin contar el espacio ocupado por los romboides) son $22.80 \mathrm{~m}$. en el de entrada y su opuesto, $21.20 \mathrm{~m}$. en los otros. Las almenas que coronan los muros perimetrales, 


\section{FORTIN-COLONLL-EN-OUIATANA-ROO Bacalap-ojulo-a la loguna)}
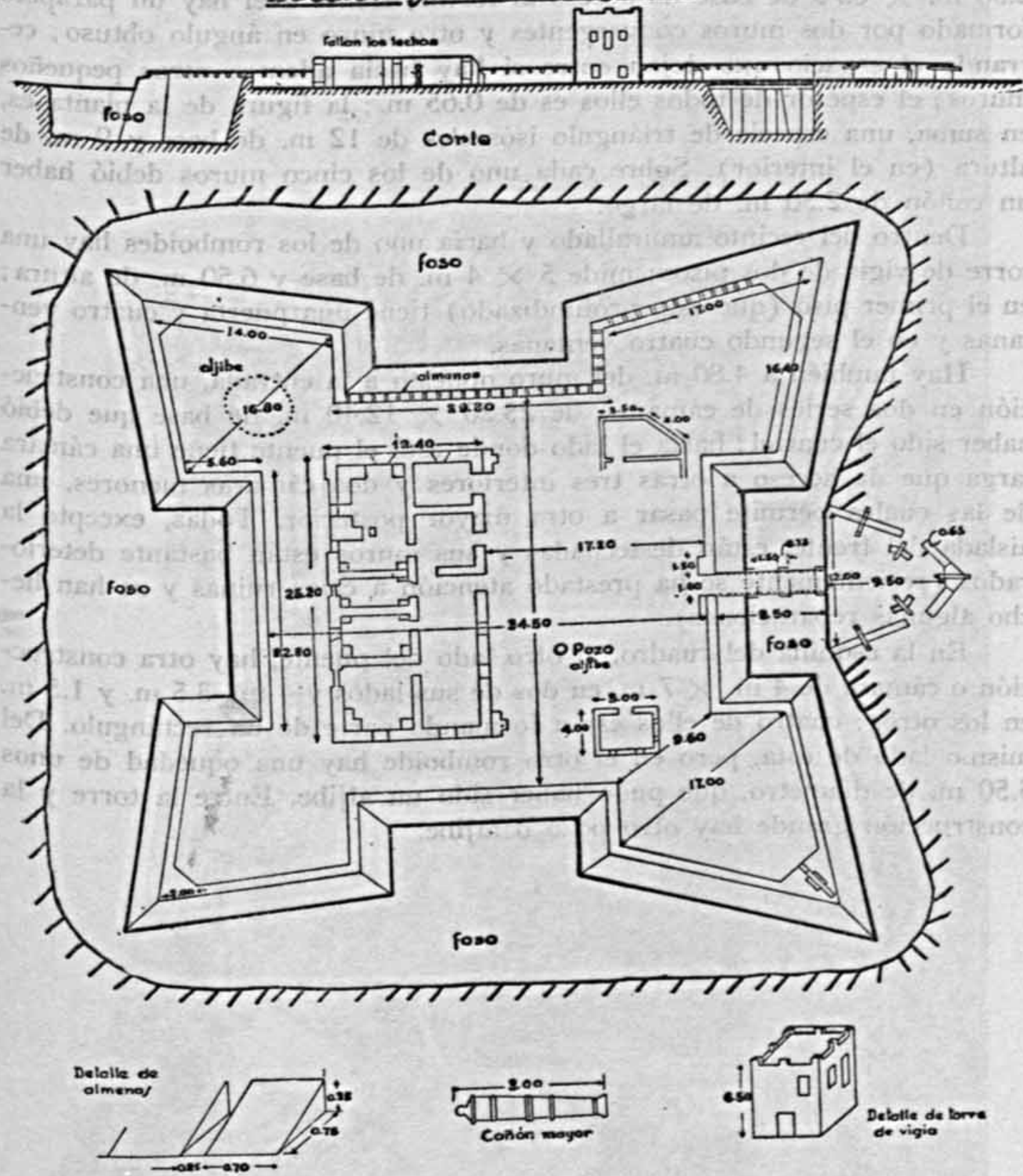
tienen una sección triangular de $0.35 \mathrm{~m}$. de alto y $0.75 \mathrm{~m}$. de largo, el ancho es de 0.70 y están separadas entre sí $0.25 \mathrm{~m}$. En largos tramos ya no existen.

Un puente de madera apoyado sobre tres pilares de $4 \mathrm{~m}$. de alto y $2.50 \mathrm{~m}$. $\times 0.75$ de base da acceso al fortin; frente a él hay un parapeto formado por dos muros convergentes y otro muro en ángulo obtuso; cerrando el espacio que dejan entre si hay hacia adentro otros pequeños muros; el espesor de todos ellos es de $0.65 \mathrm{~m}$. ; la figura de la planta es, en suma, una especie de triángulo isósceles de $12 \mathrm{~m}$. de base y $9 \mathrm{~m}$. de altura (en el interior). Sobre cada uno de los cinco muros debió haber un cañón de $2.50 \mathrm{~m}$. de largo.

Dentro del recinto amurallado $y$ hacia uno de los romboides hay una torre de vigía de dos pisos; mide $5 \times 4 \mathrm{~m}$. de base y $6.50 \mathrm{~m}$. de altura; en el primer piso (que está profundizado) tiene una puerta y cuatro ventanas y en el segundo cuatro ventanas.

Hay también a $4.80 \mathrm{~m}$. del muro opuesto a la entrada, una construcción en dos series de cámaras, de $25.20 \times 12.40 \mathrm{~m}$. de base que debió haber sido el cuartel; hacia el lado donde está el puente tiene una cámara larga que da acceso a otras tres interiores y dos cámaras menores, una de las cuales permite pasar a otra mayor posterior. Todas, excepto la aislada del frente, están destechadas y sus muros están bastante deteriorados (recientemente se ha prestado atención a estas ruinas $y$ se han hecho algunas reparaciones).

En la esquina del cuadro, al otro lado del puente, hay otra construcción o cámara de $4 \mathrm{~m}$. $\times 7 \mathrm{~m}$. en dos de sus lados y $4 \mathrm{~m}$., $3.5 \mathrm{~m}$. y $1.5 \mathrm{~m}$. en los otros; cuatro de ellos están formando patte de un rectángulo. Del mismo lado de ésta, pero en el otro romboide hay una oquedad de unos $5.50 \mathrm{~m}$. de diámetro, que pudo haber sido un aljibe. Entre la torre y la construcción grande hay otro pozo o aljibe. 


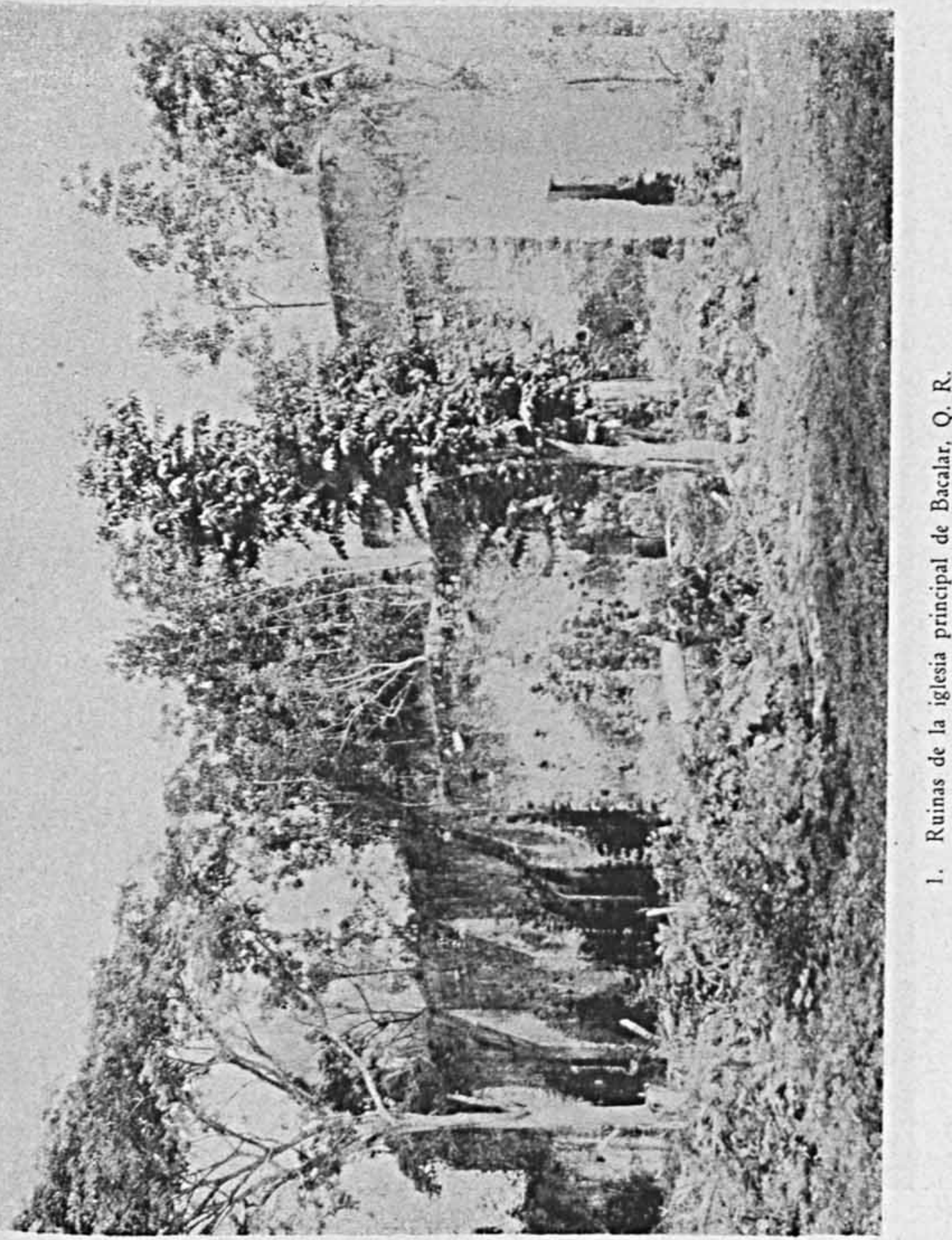


DOI: http://dx.doi.org/10.22201/iie.18703062e.1943.10.342

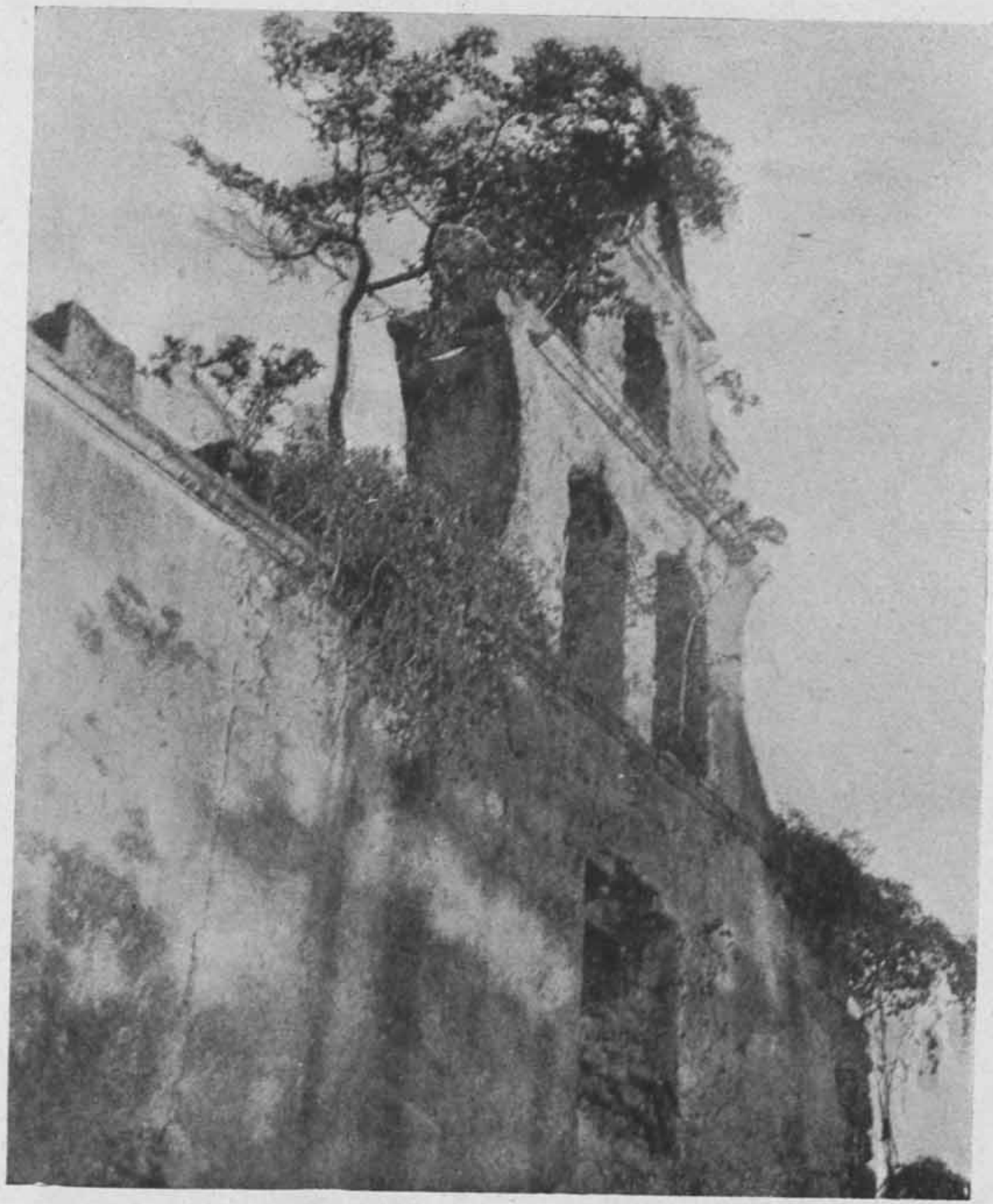

2. Fachada de la iglesia mayor de Bacalar, Q. R. 
DOI: http://dx.doi.org/10.22201/iie.18703062e.1943.10.342

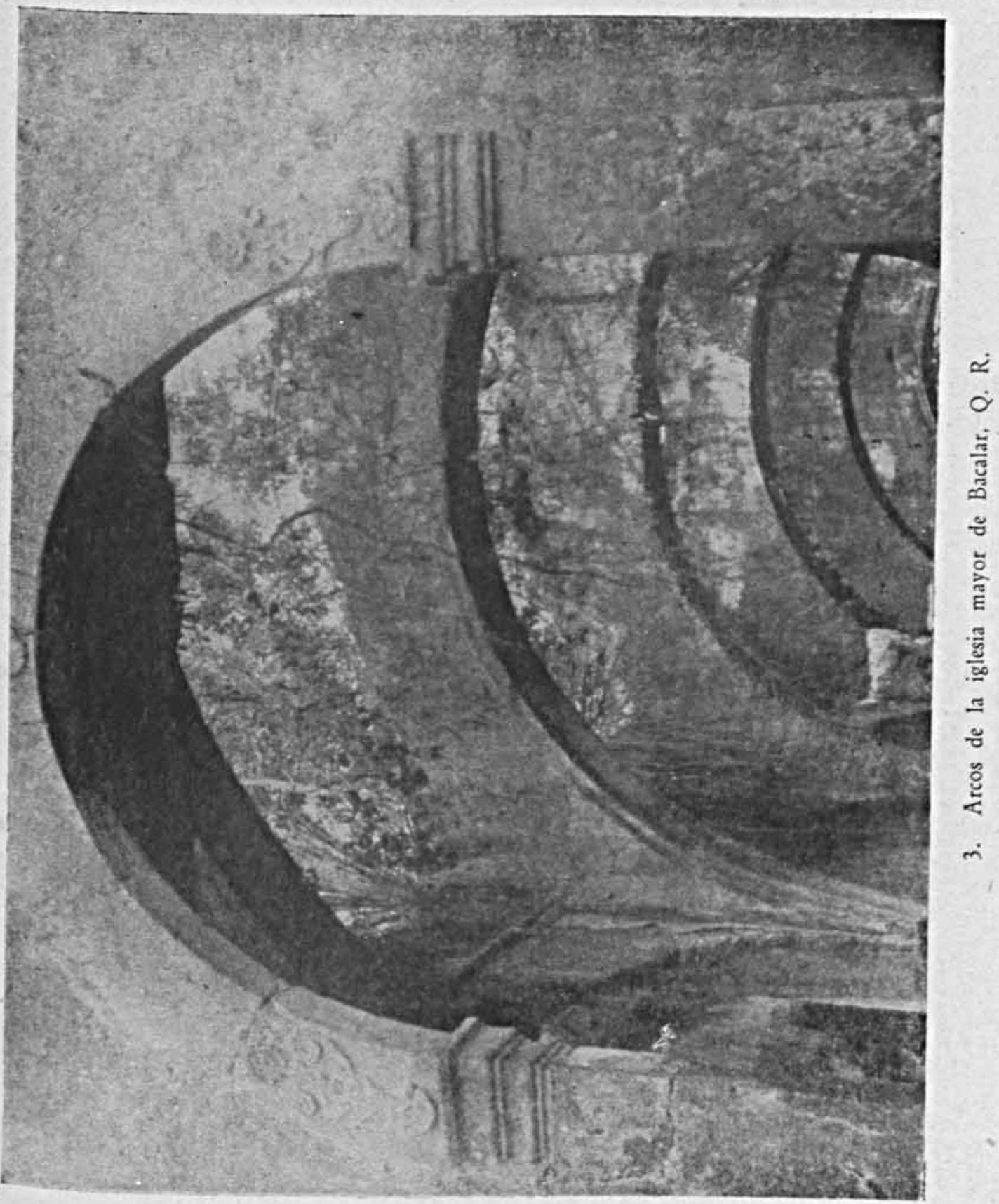




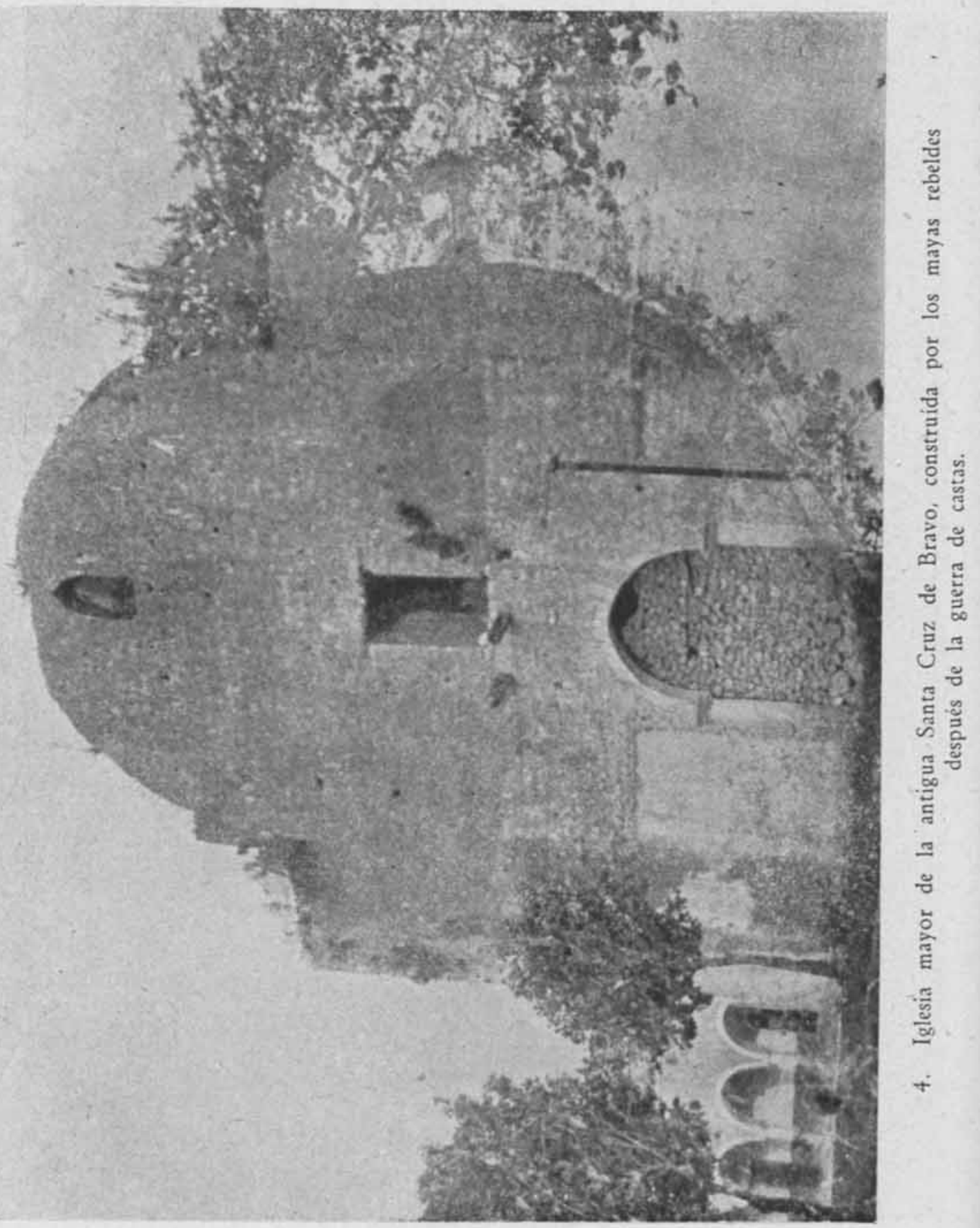




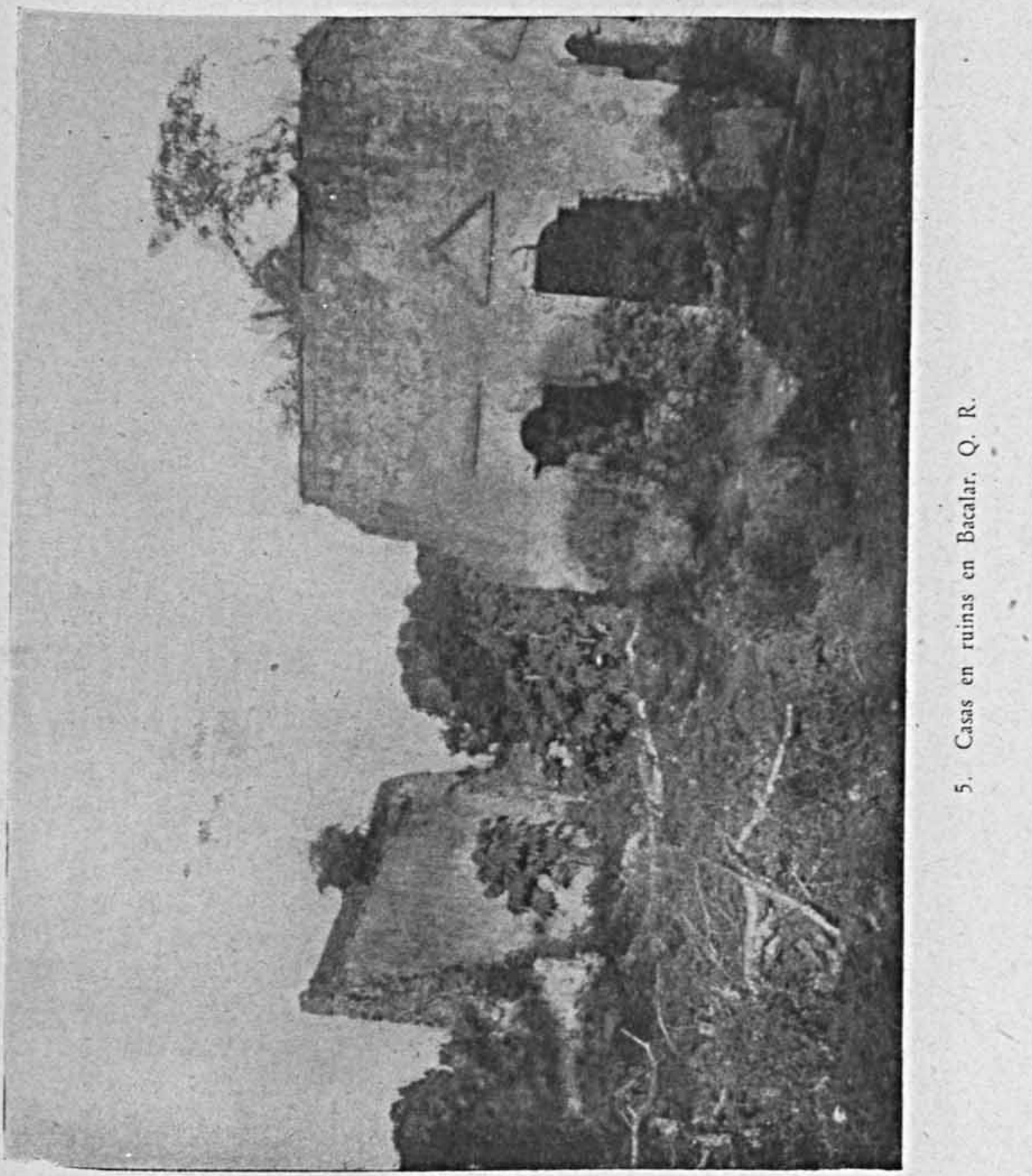


DOI: http://dx.doi.org/10.22201/iie.18703062e.1943.10.342

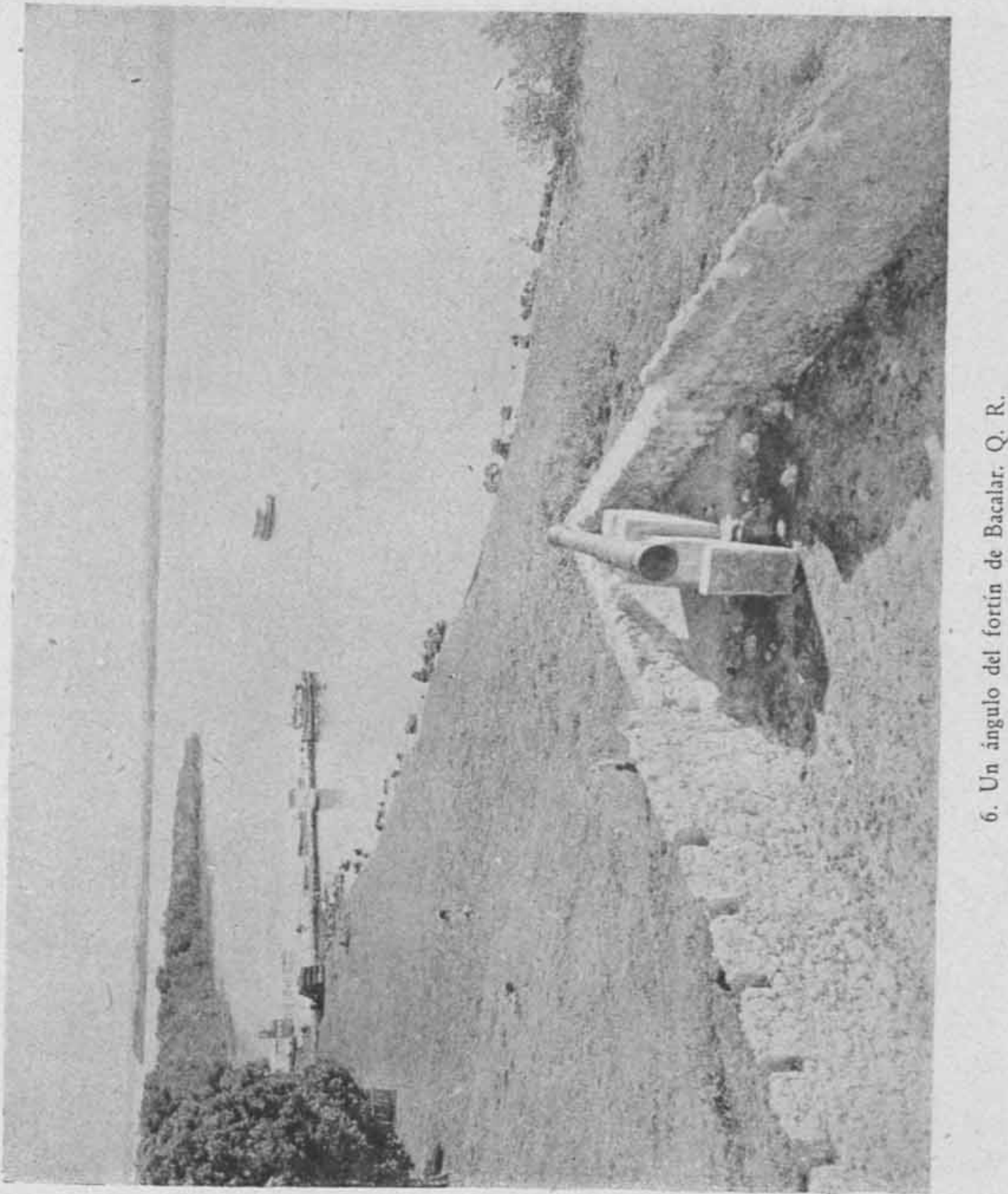

